\title{
Synthesis and Characterization of New Dihydronaphthalene Candidates as Potent Cytotoxic Agents against MCF-7 Human Cancer Cells
}

\author{
Nesreen S. Ahmed $\left(\mathbb{D},{ }^{1}\right.$ Alaadin E. Sarhan ${ }^{(D)}{ }^{1}$ Aisha A. K. Al-Ashmawy ${ }^{D},{ }^{1}$ \\ Abd El-Galil E. Amr $\mathbb{D}^{\mathbb{2}, 3}$ Mogedda E. Haiba $\mathbb{D}^{1}{ }^{1}$ and Elsayed A. Elsayed $\mathbb{D}^{4,5}$ \\ ${ }^{1}$ Department of Therapeutic Chemistry, Pharmaceutical and Drug Industries Research Division, National Research Center, \\ El Buhouth Street, Dokki, Cairo 12622, Egypt \\ ${ }^{2}$ Pharmaceutical Chemistry Department, College of Pharmacy, King Saud University, Riyadh 11451, Saudi Arabia \\ ${ }^{3}$ Applied Organic Chemistry Department, National Research Center, Cairo, Dokki 12622, Egypt \\ ${ }^{4}$ Zoology Department, Faculty of Science, King Saud University, Riyadh 11451, Saudi Arabia \\ ${ }^{5}$ Chemistry of Natural and Microbial Products Department, National Research Centre, Dokki, 12622 Cairo, Egypt
}

Correspondence should be addressed to Abd El-Galil E. Amr; aamr@ksu.edu.sa

Received 18 July 2020; Revised 15 November 2020; Accepted 11 December 2020; Published 30 December 2020

Academic Editor: Dorota Formanowicz

Copyright (c) 2020 Nesreen S. Ahmed et al. This is an open access article distributed under the Creative Commons Attribution License, which permits unrestricted use, distribution, and reproduction in any medium, provided the original work is properly cited.

\begin{abstract}
In the present work, a new series of dihydronaphthalene derivatives were synthesized starting with 6-methoxy-1-tetralone 1, and the corresponding hydrazine derivative $\mathbf{2}$. Reaction of compound $\mathbf{2}$ with aryl isothiocyanates produced thiosemicarbazides $\mathbf{3 a - d}$, which were reacted with ethyl chloroacetate to give thiazolidinone derivatives 4a-d. Pyrano thiazolecarbonitrile derivatives 5a-f were prepared by heating a mixture of compounds $\mathbf{4 a}$ or $\mathbf{4 c}$, aryl aldehydes, and malononitrile utilizing distilled water in the presence of catalytic amount of potassium hydrogen phthalate. Also, treatment of 4a with DMF-DMA under solvent-free conditions gave enaminone derivative 6, which condensed with ethyl acetoacetate or acetylacetone or malononitrile or cyanothioacetamide to give compounds 7-10, respectively. Finally, reaction of the enaminone 6 with 2-aminoimidazol or 2 aminothiazol in the presence of glacial acetic acid produced derivatives 11 and 12, respectively. Cytotoxic evaluation of eleven compounds, against MCF-7 (human breast adenocarcinoma) cell lines, was estimated. Results revealed that five of the examined compounds $5 \mathbf{a}, \mathbf{5 d}, \mathbf{5 e}, \mathbf{1 0}$, and $\mathbf{3 d}$ showed potent cytotoxic activities recording, $\mathrm{IC}_{50}$ values; $0.93 \pm 0.02,1.76 \pm 0.04,2.36 \pm 0.06$, $2.83 \pm 0.07$, and $3.73 \pm 0.09 \mu \mathrm{M}$, respectively, which were more potent than the reference used (Saturosporin, $\mathrm{IC}_{50} 6.08 \pm 0.15$ $\mu \mathrm{M})$. The new products were also examined towards normal epithelial breast cells (MCF10A). All of them showed very good safety profile with different degrees and were safer than the reference drug used. Compound 5a was the most effective against MCF-7 cells and was less toxic than Saturosporin by about 18.45-folds towards MCF01A normal cells. All the new compounds were fully characterized by the different spectral and analytical tools. Herein, detailed syntheses, spectroscopic, and biological data are reported.
\end{abstract}

\section{Introduction}

Breast cancer represents the most common cancer disease among women. It represents the second-highest rate leading cause of women mortality worldwide [1]. Chemotherapy is the most common for cancer treatment. Developing cancer drugs is essential to discover more active products with high potential [2]. This work represents an attempt to develop new therapeutic compounds of high efficacy in treating breast cancer disease. Literature reports confirmed the important diverse types of pharmaceutical activities of thiazole, pyrane, and/or pyridine derivatives. Thiazoles have concerned a great era of attention due to their association with various types of biological activities. Their derivatives 
exhibited important potency as anticancer [3-5], antibacterial [6], anti-inflammatory [7], antioxidant [8], antimalarial [9] agents, and HIV-inhibitors [10]. Also, pyrane containing derivatives have been identified as anticancer [11], antimicrobial [12], anti-inflammatory [13], and antimalarial [14] agents. Furthermore, literature survey reported that compounds containing pyridine ring demonstrated anticancer [15], antimicrobial [16], anti-inflammatory [17], antiviral [18], and antioxidant [19] activities. Based on our recent work which demonstrated that various tetralone-based derivatives verified significant inhibitory activity towards different types of cancer disease, they displayed highly significant cytotoxic activity against MCF-7 human cancer cells (breast cancer), for all the tested compounds, all of them showed activity more potent than that obtained by the reference drug (Doxorubicine) [20]. Also, significant cytotoxic effects on U373 (human glioblastoma cells) were testified [21]. Additionally, cytotoxic activity against HepG-2 (human cancer cells) was established [22]. These facts motivated us to synthesize new compounds derived from coupling of 6-methoxy-1-tetralone with different heterocyclic ring systems such as thiazole, pyrano [2,3-d] thiazole, and dihydrothiazolo [4,5-b] pyridine in one molecule aiming to construct new candidates of enhancing anticancer activity. Herein, 6-methoxy-1-tetralone was used as good building blocks to construct the desired heterocyclic products.

\section{Materials and Methods}

2.1. Chemistry. Melting points were uncorrected and were taken in open capillary tubes using Electrothermal apparatus 9100. Infrared spectra were recorded on a Shimadzu FT-IR Affinity-1 Spectrometer, Infrared spectrometer at $\mathrm{cm}^{-1}$ scale using $\mathrm{KBr}$ disc technique at Faculty of Pharmacy-Cairo University, Cairo, Egypt. ${ }^{1} \mathrm{H}$ NMR and ${ }^{13} \mathrm{C}$ NMR spectra were determined by using a Bruker High-Performance Digital FT-NMR Spectrometer Avance III $400 \mathrm{MHz}$, Faculty of Pharmacy-Cairo University, Cairo, Egypt. Chemical shifts were expressed in $\delta(\mathrm{ppm})$ downfield from TMS as an internal standard. The mass spectra were recorded on a GCMCQP 1000 EX Shimadzu gas chromatograph-mass spectrometer (GC-MS; Shimadzu Corp. Kyoto, Japan) at electron ionization (EI) of $70 \mathrm{eV}$. Elemental analyses $(\mathrm{C}, \mathrm{H}$, and $\mathrm{N}$ ) were conducted at the Micro Analytical Center of the Faculty of Science of Cairo University, Cairo, Egypt. All reagents were commercial grade and used without further purification. Reaction progress was monitored by thin-layer chromatography (TLC) on precoated $(0.75 \mathrm{~mm})$ silica gel GF254 plates (Merck Group, Darmstadt, Germany). Products were visualized under ultraviolet (UV) light.

2.1.1. Synthesis of 6-Methoxy-3, 4-dihydronaphthalen-1(2H)ylidene hydrazine 2. Compound 2 was prepared and characterized as described in our literature report [23].

2.1.2. N-(Substituted)-2-(6-methoxy-3,4-dihydronaphthalen1(2H)-ylidene) hydrazinecarbothio amide (3a-d). A mixture of compound $2(0.002 \mathrm{~mol})$ and the appropriate substituted isothiocyanates $(0.002 \mathrm{~mol})$ namely (p-bromophenyl, p-flour- ophenyl, phenoxyphenyl, or ethyl) isothiocyanate in dry benzene $(30 \mathrm{~mL})$ was refluxed for $30 \mathrm{~min}$. After cooling, the excess solvent was evaporated; the solid product was filtered off, dried, and recrystallized from ethyl alcohol to give the desired products 3a-d, respectively.

2.1.3. N-(4-Bromophenyl)-2-(6-methoxy-3,4-dihydronaphtha-len1(2H)-ylidene)hydrazine-1-carbo thioamide 3a. Yield: 91\%; m.p.: $191-193^{\circ} \mathrm{C}$; IR $\left(v_{\max } / \mathrm{cm}^{-1}\right)$ : $3381,3317(2 \mathrm{NH}) ;{ }^{1} \mathrm{H}-$ NMR (DMSO- $\left.d_{6}\right): \delta, 1.82-1.85\left(\mathrm{~m}, 2 \mathrm{H}, \mathrm{CH}_{2}, \mathrm{C}-3\right), 2.58(\mathrm{t}$, $\left.J=1.7,2 \mathrm{H}, \mathrm{CH}_{2}, \mathrm{C}-2\right), 2.7\left(\mathrm{t}, J=6.5,2 \mathrm{H}, \mathrm{CH}_{2}, \mathrm{C}-4\right), 3.79$ (s, $3 \mathrm{H}, \mathrm{OCH}_{3}$ ), 6.7-6.8 (m, 2H, Ar), 7.5-7.6 (m, 4H, Ar), 8.3 (d, $J=8.6,1 \mathrm{H}, \mathrm{Ar}, \mathrm{CH}-8), 10.0,10.5(2 \mathrm{~s}, 2 \mathrm{H}, 2 \mathrm{NH}) ;{ }^{13} \mathrm{C}-\mathrm{NMR}$ $\left(\mathrm{DMSO}-d_{6}\right): \delta ; 21.9\left(\mathrm{CH}_{2}, \mathrm{C}-3\right), 26.5(\mathrm{CH} 2, \mathrm{C}-2), 29.6$ $\left(\mathrm{CH}_{2}, \mathrm{C}-4\right), 55.6\left(\mathrm{OCH}_{3}\right), 112.7,113.6,117.8,124.8,128.0$, 128.1, 131.2, 139.1, 142.8, 150.2, 160.7 (Ar-C and $\mathrm{CN}$ ), 176.8 (C=S); MS: m/z (\%) 403, $405\left(\mathrm{M}^{+}, 37,36\right)$ consistent with the molecular formula $\mathrm{C}_{18} \mathrm{H}_{18} \mathrm{Br} \mathrm{N} \mathrm{N}_{3} \mathrm{OS}$. Anal. Calcd. C,53.47; H,4.49; N,10.39, Found C,53.69; H, 3.99; N,10.71\%.

2.1.4. N-(4-Fluorophenyl)-2-(6-methoxy-3,4-dihydronaphthalen-1(2H)-ylidene)hydrazine-1-carbo thioamide 3b. Yield: 85\%; m.p.: $154-156^{\circ} \mathrm{C}$; IR $\left(v_{\max } / \mathrm{cm}^{-1}\right): 3365,3320(2 \mathrm{NH}) ;{ }^{1} \mathrm{H}-$ NMR (DMSO- $\left.d_{6}\right): \delta, 1.8\left(\mathrm{~m}, 2 \mathrm{H}, \mathrm{CH}_{2}, \mathrm{C}-3\right), 2.6(\mathrm{t}, J=6$, $\left.2 \mathrm{H}, \mathrm{CH}_{2}, \mathrm{C}-2\right), 2.9\left(\mathrm{t}, J=6,2 \mathrm{H}, \mathrm{CH}_{2}, \mathrm{C}-4\right), 3.8(\mathrm{~s}, 3 \mathrm{H}$, $\mathrm{OCH}_{3}$ ), 6.7 (s, 1H, Ar, CH-5), 7.2-7.5 (m, 4H, Ar), 7.68 (d, $J=8.5,1 \mathrm{H}, \mathrm{Ar}), 8.2$ (d, $J=8.5,1 \mathrm{H}, \mathrm{Ar}), 8.3($ br s, $1 \mathrm{H}, \mathrm{NH})$, 9.3 (br s, $1 \mathrm{H}, \mathrm{NH}) ;{ }^{13} \mathrm{C}-\mathrm{NMR}\left(\mathrm{DMSO}-d_{6}\right): \delta, 20.5\left(\mathrm{CH}_{2}, \mathrm{C}-\right.$ 3), $26.5\left(\mathrm{CH}_{2}, \mathrm{C}-2\right), 27.9\left(\mathrm{CH}_{2}, \mathrm{C}-4\right), 55.6\left(\mathrm{OCH}_{3}\right), 111.2$, $113.6,119.4,120.8,123.4,124.4,126.4,127.1,129.8,131.1$, 133.2, 134.1, 158.2, 159.1, 168.5, (Ar-C and CN), 170.3 $(\mathrm{C}=\mathrm{S}) ; \mathrm{MS}: \mathrm{m} / \mathrm{z}(\%) 343\left(\mathrm{M}^{+}, 25\right)$ consistent with the molecular formula $\mathrm{C}_{18} \mathrm{H}_{18} \mathrm{FN}_{3} \mathrm{OS}$. Anal. Calcd. C, 62.95; H, 5.28; N, 12.24,Found C,62.53; H, 4.73; N,11.81\%.

2.1.5. 2-(6-Methoxy-3,4-dihydronaphthalen-1(2H)-ylidene)-N(4-phenoxyphenyl)-hydrazine-1-carbo thioamide 3c. Yield: 94\%; m.p.: $171^{\circ} \mathrm{C}$; IR $\left(v_{\max } / \mathrm{cm}^{-1}\right): 3325,3275(2 \mathrm{NH}) ;{ }^{1} \mathrm{H}-$ NMR (DMSO- $\left.d_{6}\right): \delta, 1.85\left(\mathrm{~m}, 2 \mathrm{H}, \mathrm{CH}_{2}-3\right), 2.7(\mathrm{t}, J=6.5,2 \mathrm{H}$, $\left.\mathrm{CH}_{2}-2\right), 2.86\left(\mathrm{t}, J=6,2 \mathrm{H}, \mathrm{CH}_{2}-4\right), 3.8\left(\mathrm{~s}, 3 \mathrm{H}, \mathrm{OCH}_{3}\right), 6.2(\mathrm{t}$, $J=6.5,1 \mathrm{H}, \mathrm{C}-4^{\prime}$, phenyl ring), 6.78 (s, 1H, Ar, CH-5), 7.1-7.3 $(\mathrm{m}, 8 \mathrm{H}, \mathrm{Ar}$ and $\mathrm{NH}), 7.65(\mathrm{~d}, J=8.5,1 \mathrm{H}, \mathrm{Ar}), 8.4(\mathrm{~d}, J=8.5$, $1 \mathrm{H}, \mathrm{Ar}$ ), 8.6 (br s, $1 \mathrm{H}, \mathrm{NH}) ;{ }^{13} \mathrm{C}-\mathrm{NMR}$ (DMSO- $\left.d_{6}\right): \delta, 20.5$ $\left(\mathrm{CH}_{2}-3\right), 27.9\left(\mathrm{CH}_{2}-2\right), 29.5\left(\mathrm{CH}_{2}-4\right), 55.6\left(\mathrm{OCH}_{3}\right), 111.2$, $113.6,119.4,120.8,123.4,124.4,126.4,127.1,129.8,130.0$, 133.2, 134.1, 158.2, 159.1, 168.5, (Ar-C and CN), 170.3 $(\mathrm{C}=\mathrm{S})$; MS: $\mathrm{m} / \mathrm{z}(\%) 417\left(\mathrm{M}^{+}, 53\right)$ consistent with the molecular formula $\mathrm{C}_{24} \mathrm{H}_{23} \mathrm{~N}_{3} \mathrm{O}_{2}$ S. Anal. Calcd. C, 69.04; H, 5.55; N, 10.06, Found C,68.67; H, 5.16; N,9.68\%.

2.1.6. $\mathrm{N}$-(4-Ethyl)-2-(6-methoxy-3,4-dihydronaphthalen-1(2H)ylidene)hydrazine-1-carbothioamide 3d. Yield: 93\%; m.p.: $150-153^{\circ} \mathrm{C}$; IR $\left(v_{\max } / \mathrm{cm}^{-1}\right): 3370,3281(2 \mathrm{NH}) ;{ }^{1} \mathrm{H}-\mathrm{NMR}$ $\left(\mathrm{DMSO}-d_{6}\right): \delta, 1.1\left(\mathrm{t}, J=5.9,3 \mathrm{H},-\mathrm{CH}_{2} \mathrm{CH}_{3}\right), 1.79(\mathrm{~m}, 2 \mathrm{H}$, $\left.\mathrm{CH}_{2}, \mathrm{C}-3\right), 2.6\left(\mathrm{t}, J=6.4,2 \mathrm{H}, \mathrm{CH}_{2}, \mathrm{C}-2\right), 2.7(\mathrm{t}, J=5.8,2 \mathrm{H}$, $\left.\mathrm{CH}_{2}, \mathrm{C}-4\right), 3.59-3.64$ (q, 2H, $\left.-\mathrm{CH}_{2}-\mathrm{CH}_{3}\right), 3.79(\mathrm{~s}, 3 \mathrm{H}$, $\left.\mathrm{OCH}_{3}\right), 6.7$ (s, 1H, CH-5), $6.8(\mathrm{~d}, J=8.8,1 \mathrm{H}, \mathrm{CH}-7), 8.2$ (d, $J=8.8,1 \mathrm{H}, \mathrm{CH}-8), 8.4$ (br s, $1 \mathrm{H}, \mathrm{NH}), 9.9$ (s, $1 \mathrm{H}, \mathrm{NH}) ;{ }^{13} \mathrm{C}-$ NMR (DMSO- $\left.d_{6}\right): \delta, 14.8\left(\mathrm{CH}_{2} \mathrm{CH}_{3}\right), 22.3\left(\mathrm{CH}_{2}-3\right), 27.01$ $\left(\mathrm{CH}_{2}-2\right), 29.6\left(\mathrm{CH}_{2}-4\right), 38.8\left(\underline{\mathrm{CH}}_{2} \mathrm{CH}_{3}\right), 55.5\left(\mathrm{OCH}_{3}\right)$, 
112.7, 113.5, 125.9, 128.7, 142.6, 148.3, 160.7 (Ar-C and CN), (177 C=S); MS: $\mathrm{m} / \mathrm{z}(\%) 277\left(\mathrm{M}^{+}, 65\right)$ consistent with the molecular formula $\mathrm{C}_{14} \mathrm{H}_{19} \mathrm{~N}_{3} \mathrm{OS}$. Anal. Calcd. C, 60.62; $\mathrm{H}$, $6.90 ; \mathrm{N}, 15.15$; Found C, 60.13; H, 6.63; N, 14.98\%.

2.1.7. 2-Substituted-3-((6-methoxy-3,4-dihydronaphthalin$1(2 \mathrm{H})$-ylidene)amino)thiazolidin-4-ones $4 a-d$. To a solution of $3 \mathbf{a}-\mathbf{d}(0.001 \mathrm{~mol})$ in ethanol $(20 \mathrm{~mL})$, ethyl chloroacetate $(0.001 \mathrm{~mol})$ was added and refluxed for $4 \mathrm{~h}$. After cooling, the solid product was filtered off, dried, and recrystallized from ethanol to give the desired compounds $\mathbf{4 a - d .}$

2.1.8. 2-((4-Bromophenyl)imino)-3-((6-methoxy-3,4-dihydronaphthalen-1(2H)-ylidene)amino) thiazolidin-4-one $4 a$. Yield: $81 \%$; m.p.: $183^{\circ} \mathrm{C}$; IR $\left(v_{\max } / \mathrm{cm}^{-1}\right): 1710(\mathrm{C}=\mathrm{O}) ;{ }^{1} \mathrm{H}-$ NMR (DMSO- $\left.d_{6}\right): \delta, 1.8(\mathrm{~m}, 2 \mathrm{H}, \mathrm{CH}-3), 2.55(\mathrm{t}, J=6.4,2 \mathrm{H}$, $\left.\mathrm{CH}_{2}-2\right), 2.7\left(\mathrm{t}, J=6,2 \mathrm{H}, \mathrm{CH}_{2}-4\right), 3.7$ (s, 3H, $\left.\mathrm{OCH}_{3}\right), 4.05$ (s, $2 \mathrm{H}, \mathrm{CH}_{2}$ thiazolidinone), 6.7-6.8 (m, $\left.3 \mathrm{H}, \mathrm{Ar}\right), 7.3$ (d, $J=8.5$, $1 \mathrm{H}, \mathrm{Ar}), 7.5-7.6$ (m, 2H, Ar), 8.3 (d, J=8.5, 1H, Ar, CH-8); ${ }^{13} \mathrm{C}-\mathrm{NMR}\left(\mathrm{DMSO}-d_{6}\right): \delta ; 22.5\left(\mathrm{CH}_{2}, \mathrm{C}-3\right), 26.8\left(\mathrm{CH}_{2}, \mathrm{C}-2\right)$, $29.7\left(\mathrm{CH}_{2}, \mathrm{C}-4\right), 32.9\left(\mathrm{CH}_{2}\right.$, thizolidinone $), 55.6\left(\mathrm{OCH}_{3}\right)$, $110.7,112.7,113.6,117.8,124.8,128.0,128.1,131.2,139.1$, $142.8,150.2,160.7,167.4($ Ar-C, $\mathrm{CN}$ and $\mathrm{C}=\mathrm{O}$ ); MS: $\mathrm{m} / \mathrm{z}$ (\%): 443, $445\left(\mathrm{M}^{+}, 5,5\right)$ consistent with the molecular formula $\mathrm{C}_{20} \mathrm{H}_{18} \mathrm{BrN}_{3} \mathrm{O}_{2} \mathrm{~S}$. Anal. Calcd. C, 54.06; H, 4.08; N, 9.46; Found C, 53.61; H, 3.79; N,8.91\%.

2.1.9. 2-((4-Fluorophenyl)imino)-3-((6-methoxy-3,4-dihydronaphthalen-1(2H)-ylidene)amino) thiazolidin-4-one $4 b$. Yield: $89 \%$; m.p.: $190^{\circ} \mathrm{C}$; IR $\left(v_{\max } / \mathrm{cm}^{-1}\right): 1728(\mathrm{C}=\mathrm{O}) ;{ }^{1} \mathrm{H}-$ NMR (DMSO- $\left.d_{6}\right): \delta, 1.9\left(\mathrm{~m}, 2 \mathrm{H}, \mathrm{CH}_{2}-3\right), 2.7(\mathrm{t}, J=5.9,2 \mathrm{H}$, $\left.\mathrm{CH}_{2}-2\right), 2.9\left(\mathrm{t}, J=6.5,2 \mathrm{H}, \mathrm{CH}_{2}-4\right), 3.8\left(\mathrm{~s}, 3 \mathrm{H}, \mathrm{OCH}_{3}\right), 4.06$ (s, 2H, thiazolidinone), $6.6(\mathrm{~s}, 1 \mathrm{H}, \mathrm{Ar}, \mathrm{CH}-5), 6.8-6.9(\mathrm{~m}$, $3 \mathrm{H}, \mathrm{Ar}), 7.1-7.4$ (m, 2H, Ar), 8.3 (d, J=9.3, 1H, Ar, CH-8); ${ }^{13} \mathrm{C}-\mathrm{NMR}\left(\mathrm{DMSO}-d_{6}\right): \delta, 21.4\left(\mathrm{CH}_{2}-3\right), 27.4\left(\mathrm{CH}_{2}-2\right), 29.6$ $\left(\mathrm{CH}_{2}-4\right), 32.7 \mathrm{CH}_{2}$ thiazolidinone $), 55.3\left(\mathrm{OCH}_{3}\right), 111.03$, $112.9,113.2,113.4,114.2,116.2,116.8,124.2,125.5,128.1$, 129.6, 130.5, 143.4, 146.9, 161.7, 162.9 (Ar-C and CN), 171 $(\mathrm{C}=\mathrm{O})$; MS: $\mathrm{m} / \mathrm{z}(\%) 383,\left(\mathrm{M}^{+}, 1\right)$ consistent with the molecular formula $\mathrm{C}_{20} \mathrm{H}_{18} \mathrm{FN}_{3} \mathrm{O}_{2} \mathrm{~S}$. Anal. Calcd. C, 62.65; H, 4.73; N, 10.96; Found C, 62.34; H, 7.53; N,10.75\%.

2.1.10. 3-((6-Methoxy-3,4-dihydronaphthalen-1(2H)-ylidene) amino)-2-((4-phenoxyphenyl)imino) thiazolidin-4-one $4 c$. Yield: $94 \%$; m.p.: $171^{\circ} \mathrm{C}$; IR $\left(v_{\max } / \mathrm{cm}^{-1}\right): 1717(\mathrm{C}=\mathrm{O}) ;{ }^{1} \mathrm{H}-$ NMR (DMSO- $\left.d_{6}\right): \delta, 1.86\left(\mathrm{~m}, 2 \mathrm{H}, \mathrm{CH}_{2}-3\right), 2.7(\mathrm{t}, J=6.5$, $\left.2 \mathrm{H}, \mathrm{CH}_{2}-2\right), 2.8\left(\mathrm{t}, J=6,2 \mathrm{H}, \mathrm{CH}_{2}-4\right), 3.8\left(\mathrm{~s}, 3 \mathrm{H}, \mathrm{OCH}_{3}\right.$ ), 3.99 (s, $2 \mathrm{H}, \mathrm{CH}_{2}$ thiazolidinone), 6.2 (t, J=6.5, $1 \mathrm{H}, \mathrm{C}-4$, phenyl ring), 6.7 (s, 1H, Ar, CH-5), 7.1-7.3 (m, 7H, Ar), 7.6 (d, $J=8.5,2 \mathrm{H}, \mathrm{Ar}), 8.3$ (d, $J=8.5,1 \mathrm{H}, \mathrm{Ar}) ;{ }^{13} \mathrm{C}-\mathrm{NMR}$ (DMSO$\left.d_{6}\right): \delta ; 20.5\left(\mathrm{CH}_{2}-3\right), 27.9\left(\mathrm{CH}_{2}-2\right), 29.5\left(\mathrm{CH}_{2}-4\right), 32.6\left(\mathrm{CH}_{2}\right.$ thiazolidinone), $55.6\left(\mathrm{OCH}_{3}\right), 111.2,113.6,119.4,120.8$, $123.4,124.4,126.4,127.1,129.8,130.0,133.2,134.1,145.8$, 158.2, 159.1, 160.6, (Ar-C and CN), $177.1 \mathrm{C}=\mathrm{O}$ ); MS: $\mathrm{m} / \mathrm{z}$ (\%) $457\left(\mathrm{M}^{+}, 67\right)$ consistent with the molecular formula $\mathrm{C}_{26} \mathrm{H}_{23} \mathrm{~N}_{3} \mathrm{O}_{3} \mathrm{~S}$. Anal. Calcd. C, 68.25; H, 5.07; N, 9.18; Found C, 69.12; H, 4.62; N,8.71\%.

2.1.11. 2-(Ethylimino)-3-((6-methoxy-3,4-dihydronaphthalen1(2H)-ylidene)amino)thiazolidin-4-one 4d. Yield: 76\%; m.p.: $117^{\circ} \mathrm{C}$; IR $\left(v_{\max } / \mathrm{cm}^{-1}\right): 1707(\mathrm{C}=\mathrm{O}) ;{ }^{1} \mathrm{H}-\mathrm{NMR}\left(\mathrm{DMSO}-d_{6}\right): \delta$, $1.2\left(\mathrm{t}, J=7,3 \mathrm{H},-\mathrm{CH}_{2}-\mathrm{CH}_{3}\right), 1.7-1.8\left(\mathrm{~m}, 2 \mathrm{H}, \mathrm{CH}_{2}-3\right), 2.7(\mathrm{t}$, $\left.J=5.8,2 \mathrm{H}, \mathrm{CH}_{2}-2\right), 2.8\left(\mathrm{t}, J=6.5,2 \mathrm{H}, \mathrm{CH}_{2}-4\right), 3.74-3.79(\mathrm{~m}$, $5 \mathrm{H}, \mathrm{OCH}_{3}$ and $\left.-\mathrm{CH}_{2} \mathrm{CH}_{3}\right), 3.9\left(\mathrm{~s}, 2 \mathrm{H}, \mathrm{CH}_{2}\right.$ thiazolidinone), 6.7 (s, 1H, Ar, CH-5), 6.8 (d, J=8.8, 1H, Ar, CH-7), 8.05 (d, $J=8.8, \quad 1 \mathrm{H}, \quad \mathrm{Ar}, \mathrm{CH}-8) ;{ }^{13} \mathrm{C}-\mathrm{NMR}$ (DMSO- $\left.d_{6}\right): \delta, 12.6$ $\left(\mathrm{CH}_{2} \mathrm{CH}_{3}\right), 22.2\left(\mathrm{CH}_{2}-3\right), 27.1\left(\mathrm{CH}_{2}-2\right), 29.9\left(\mathrm{CH}_{2}-4\right), 32.4$ $\left(\mathrm{CH}_{2}\right.$ thiazolidinone $), 38.2\left(\mathrm{CH}_{2} \mathrm{CH}_{3}\right), 55.6\left(\mathrm{OCH}_{3}\right), 113.06$, 113.6, 125.2, 126.8, 143.1, 161.0, 161.1, 161.3, (Ar-C and $\mathrm{CN}), 172.3,(\mathrm{C}=\mathrm{O})$; MS: $\mathrm{m} / \mathrm{z}(\%): 317\left(\mathrm{M}^{+}, 68\right)$ consistent with the molecular formula $\mathrm{C}_{16} \mathrm{H}_{19} \mathrm{~N}_{3} \mathrm{O}_{2} \mathrm{~S}$. Anal. Calcd. C, 60.55; $\mathrm{H}$, 6.03 ; N, 13.24; Found C, 60.09; H, 5.74; N, 12.88\%.

2.1.12. 5-Amino-2-(4-substitutedimino)-3-((6-methoxy-3,4-di hydronaphthalen-1(2H)-ylidene) amino)-7-(4-substitutedphenyl)-3,7-dihydro-2H-pyrano [2,3-d]thiazole-6-carbonitrile $5 a-f$. To a mixture of thiazolidinone derivatives $4 a$ or $4 \mathbf{c}$ (0.001 mol), aryl aldehyde, namely, 4-methoxy benzaldehyde, 4-nitrobenzaldehyde and 2-furaldehyde (0.001 mole), and malononitrile $(0.001$ mole), potassium hydrogen phthalate (KHP) $(25 \mathrm{~mol} \%)$ in distilled water $(5 \mathrm{~mL})$, was added. The mixture was heated at $50^{\circ} \mathrm{C}$, after completion of the reaction and cooling, and the solid product was collected by filtration, washed with distilled water, dried, and recrystallized from dilute ethanol to give compounds (5a-f), respectively.

2.1.13. 5-Amino-2-((4-bromophenyl)imino)-3-((6-methoxy-3, 4-dihydronaphthalen-1(2H)-ylidene) amino)-7-(4-methoxyphenyl)-3,7-dihydro-2H-pyrano [2,3-d]thiazole-6-carbonitrile 5a. Yield: $78 \%$; m.p.: $247^{\circ} \mathrm{C}$; IR $\left(v_{\max } / \mathrm{cm}^{-1}\right): 3470,3366$ $\left(\mathrm{NH}_{2}\right), 2208(\mathrm{CN}) ;{ }^{1} \mathrm{H}-\mathrm{NMR}\left(\mathrm{DMSO}-d_{6}\right): \delta, 1.7(\mathrm{~m}, 2 \mathrm{H}$, $\left.\mathrm{CH}_{2}-3\right), 2.57\left(\mathrm{t}, J=6.2,2 \mathrm{H}, \mathrm{CH}_{2}-2\right), 2.73(\mathrm{t}, J=5.7,2 \mathrm{H}$, $\left.\mathrm{CH}_{2}-4\right), 3.74\left(\mathrm{~s}, 6 \mathrm{H}, 2 \mathrm{OCH}_{3}\right), 3.78(\mathrm{~s}, 1 \mathrm{H}, \mathrm{CH}-4$, pyran), 4.06 (s, 2H, NH $\mathrm{NH}_{2}, 6.7$ (s, 1H, Ar, H-5), 6.8 (d, J=8.8, 1H, Ar), 7.09-7.23 (m, 4H, Ar), 7.40-7.5 (m, 4H, Ar), 8.05 (d, $J=8.8,1 \mathrm{H}, \mathrm{Ar}, \mathrm{H}-8) .{ }^{13} \mathrm{C}-\mathrm{NMR}\left(\mathrm{DMSO}-d_{6}\right): \delta, 22.2\left(\mathrm{CH}_{2}-\right.$ 3), $27.1\left(\mathrm{CH}_{2}-2\right), 29.6\left(\mathrm{CH}_{2}-4\right), 32.6(\mathrm{CH}-4$, pyran $), 45.7$ (C-5, pyran), $55.7\left(2 \mathrm{OCH}_{3}\right), 65.7$ (C-3, pyran), 113.0, 113.76, 118.6, 119.8, 124.6, 125.2, 126.9, 130.1, 130.4, 130.7, 143.0, 156.3, 157.2, 161.1, 161.5, 162.1, 165.9, 168.1, 169.0 (Ar-C and CN); MS: m/z (\%): $628.630\left(\mathrm{M}^{+}, 100,98\right)$ consistent with the molecular formula $\mathrm{C}_{31} \mathrm{H}_{26} \mathrm{BrN}_{5} \mathrm{O}_{3} \mathrm{~S}$. Anal. Calcd. C, 59.24; H, 4.17; N, 11.14; Found C, 60.23; H, 3.71; N, $10.96 \%$.

2.1.14. 5-Amino-2-((4-bromophenyl)imino)-3-((6-methoxy-3,4dihydronaphthalen-1(2H)-ylidene) amino)-7-(4-nitrophenyl)3,7-dihydro-2H-pyrano [2,3-d] thiazole-6-carbonitrile $5 b$. Yield: 56\%; m.p.: $213^{\circ} \mathrm{C}$; IR $\left(v_{\max } / \mathrm{cm}^{-1}\right): 3450,3373\left(\mathrm{NH}_{2}\right), 2195$ $(\mathrm{CN}) ;{ }^{1} \mathrm{H}-\mathrm{NMR}\left(\mathrm{DMSO}-d_{6}\right): \delta, 1.9\left(\mathrm{~m}, 2 \mathrm{H}, \mathrm{CH}_{2}-3\right), 2.7(\mathrm{t}$, $\left.J=6.2,2 \mathrm{H}, \mathrm{CH}_{2}-2\right), 2.9\left(\mathrm{t}, J=5.7,2 \mathrm{H}, \mathrm{CH}_{2}-4\right), 3.8(\mathrm{~s}, 3 \mathrm{H}$, $\left.\mathrm{OCH}_{3}\right), 4.0$ (s, 1H, CH-4, pyran), 6.7 (s, 1H, Ar, H-5), 7.4$7.9\left(\mathrm{~m}, 11 \mathrm{H}, \mathrm{Ar}\right.$ and $\left.\mathrm{NH}_{2}\right), 8.3(\mathrm{~d}, J=8.2,1 \mathrm{H}, \mathrm{Ar}, \mathrm{H}-8) .{ }^{13} \mathrm{C}-$ NMR (DMSO- $\left.d_{6}\right): \delta, 22.3\left(\mathrm{CH}_{2}-3\right), 27.4\left(\mathrm{CH}_{2}-2\right), 29.9$ $\left(\mathrm{CH}_{2}-4\right), 31.7$ (CH-4, pyran), 45.5 (CH-5, pyran), 55.67 $\left(\mathrm{OCH}_{3}\right), 67.8$ (C-3, pyran), 113.0, 113.76, 118.6, 119.8, $124.6,125.2,126.9,130.4,130.7,140.7,143.0,146.0,156.3$, 159.5, 161.1, 161.5, 162.1, 165.9, 168.1 (Ar-C and CN); MS: $\mathrm{m} / \mathrm{z}(\%): 641,642\left(\mathrm{M}^{+}, 1513.9\right)$ consistent with the molecular 
formula $\mathrm{C}_{30} \mathrm{H}_{23} \mathrm{BrN}_{6} \mathrm{O}_{4} \mathrm{~S}$. Anal. Calcd. C, 55.99; H, 3.60; N, 13.06; Found C, 55.39; H, 3.41; N, 12.81\%.

2.1.15. 5-Amino-2-((4-bromophenyl)imino)-7-(4-furan-2-yl)3-((6-methoxy-3,4-dihydronaphthalen -1(2H)-ylidene)amino)3,7-dihydro-2H-pyrano [2,3-d] thiazole-6-carbonitrile 5c. Yield: 72\%; m.p.: $255^{\circ} \mathrm{C}$; IR $\left(v_{\max } / \mathrm{cm}^{-1}\right): 3428,3310\left(\mathrm{NH}_{2}\right), 2210$ (CN); ${ }^{1} \mathrm{H}-\mathrm{NMR}$ (DMSO-d $\left.{ }_{6}\right): \delta, 1.7\left(\mathrm{~m}, 2 \mathrm{H}, \mathrm{CH}_{2}-3\right), 2.57$ (t, $\left.J=6.5,2 \mathrm{H}, \mathrm{CH}_{2}-2\right), 2.7\left(\mathrm{t}, J=5.7,2 \mathrm{H}, \mathrm{CH}_{2}-4\right), 3.7(\mathrm{~s}, 3 \mathrm{H}$, $\left.\mathrm{OCH}_{3}\right), 4.05$ (s, H, CH-4, pyran), $5.06\left(\mathrm{~s}, 2 \mathrm{H}, \mathrm{NH}_{2}\right), 6.7$ (s, 1H, Ar, H-5), 6.8 (t, J=5.9, 1H, furyl), 7.0-7.5 (m, 5H, Ar), $8.0(\mathrm{~d}, J=9.3,1 \mathrm{H}, \mathrm{Ar}), 8.1(\mathrm{~d}, J=9.3,1 \mathrm{H}, \mathrm{Ar})$, $8.3(\mathrm{~d}, J=8.5,1 \mathrm{H}, \mathrm{Ar}, \mathrm{H}-8) ;{ }^{13} \mathrm{C}-\mathrm{NMR}$ (DMSO- $\left.d_{6}\right): \delta$, $22.2\left(\mathrm{CH}_{2}-3\right), 27.1\left(\mathrm{CH}_{2}-2\right), 29.7\left(\mathrm{CH}_{2}-4\right), 32.6(\mathrm{CH}-4$, pyran), 45.7 (C-5, pyran), $55.6\left(\mathrm{OCH}_{3}\right), 67.9$ (C-3, pyran), $106.2,107.5,110.8,118.6,119.8,124.6,125.2,130.1,130.7$, $143.0,146.3,156.3,157.2,161.1,161.5,162.1,165.9,168.1$, 169.0 (Ar-C and CN); MS: m/z (\%): 587, $590\left(\mathrm{M}^{+}, 59,58\right)$ consistent with the molecular formula $\mathrm{C}_{28} \mathrm{H}_{22} \mathrm{BrN}_{5} \mathrm{O}_{3} \mathrm{~S}$. Anal. Calcd. C, 57.15; H, 3.77; N, 11.90; Found C, 56.87; $\mathrm{H}, 3.63 ; \mathrm{N}, 11.48 \%$.

2.1.16. 5-Amino-3-((6-methoxy-3,4-dihydronaphthalen-1(2H)ylidene)amino)-7-(4-methoxyphenyl) -2-((4-phenoxyphenyl) imino)-3,7-dihydro-2H-pyrano [2,3-d]thiazole-6-carbonitrile 5d. Yield: $81 \%$; m.p.: $209^{\circ} \mathrm{C}$; IR $\left(v_{\max } / \mathrm{cm}^{-1}\right): 3444,3370$ $\left(\mathrm{NH}_{2}\right), 2215(\mathrm{CN}) ;{ }^{1} \mathrm{H}-\mathrm{NMR}\left(\mathrm{DMSO}-d_{6}\right): \delta, 1.7(\mathrm{~m}, 2 \mathrm{H}$, $\left.\mathrm{CH}_{2}-3\right), 2.4\left(\mathrm{t}, J=6.2,2 \mathrm{H}, \mathrm{CH}_{2}-2\right), 2.7\left(\mathrm{t}, J=5.7,2 \mathrm{H}, \mathrm{CH}_{2}-\right.$ 4), $3.72\left(\mathrm{~s}, 3 \mathrm{H}, \mathrm{OCH}_{3}\right), 3.78\left(\mathrm{~s}, 3 \mathrm{H}, \mathrm{OCH}_{3}\right), 4.05(\mathrm{~s}, 1 \mathrm{H}$, $\mathrm{CH}-4$, pyran), 6.7 (s, 1H, Ar, H-5), 6.8-7.3 (m, 10H, Ar), $7.4(\mathrm{~d}, J=7.6,2 \mathrm{H}, \mathrm{Ar}), 8.02(\mathrm{~d}, J=8.5,2 \mathrm{H}, \mathrm{Ar}), 8.1$ (d, $J=8.5,1 \mathrm{H}, \mathrm{Ar}, \mathrm{H}-8), 10.5\left(\mathrm{~s}, 2 \mathrm{H}, \mathrm{NH}_{2}\right) ;{ }^{13} \mathrm{C}-\mathrm{NMR}$ (DMSO$\left.d_{6}\right): \delta, 21.9\left(\mathrm{CH}_{2}-3\right), 26.5\left(\mathrm{CH}_{2}-2\right), 29.6\left(\mathrm{CH}_{2}-4\right), 32.6(\mathrm{CH}-$ 4 , pyran), 45.7 (C-5, pyran), 55.64, $55.66\left(2 \mathrm{OCH}_{3}\right), 65.9(\mathrm{C}-$ 3, pyran), 113.0, 113.76, 114.8, 117.2, 118.6, 119.8, 120.9, $124.6,125.2,126.9,130.1,130.4,131.2,134.1,143.0,156.3$, $157.2,161.1,161.5,162.1,165.9,168.1,169.0$ (Ar-C and $\mathrm{CN})$; MS: $\mathrm{m} / \mathrm{z}(\%): 641\left(\mathrm{M}^{+}, 42\right)$ consistent with the molecular formula $\mathrm{C}_{37} \mathrm{H}_{31} \mathrm{~N}_{5} \mathrm{O}_{4} \mathrm{~S}$. Anal. Calcd. C, 69.25; H, 4.87; N, 10.90; Found C, 69.09; H, 4.63; N, 10.67\%.

2.1.17. 5-Amino-3-((6-methoxy-3,4-dihydronaphthalen-1(2H)ylidene)amino)-7-(4-nitrophenyl)-2-((4-phenoxyphenyl)imino)-3,7-dihydro-2H-pyrano [2,3-d] thiazole-6-carbonitrile 5e. Yield: 61\%; m.p.: $223^{\circ} \mathrm{C}$; IR $\left(v_{\max } / \mathrm{cm}^{-1}\right): 3465,3360\left(\mathrm{NH}_{2}\right), 2197$ $(\mathrm{CN}) ;{ }^{1} \mathrm{H}-\mathrm{NMR}\left(\mathrm{DMSO}-d_{6}\right): \delta, 1.7\left(\mathrm{~m}, 2 \mathrm{H}, \mathrm{CH}_{2}-3\right), 1.8(\mathrm{t}$, $\left.J=6.2,2 \mathrm{H}, \mathrm{CH}_{2}-2\right), 2.9\left(\mathrm{t}, J=5.7,2 \mathrm{H}, \mathrm{CH}_{2}-4\right), 3.8(\mathrm{~s}, 3 \mathrm{H}$, $\mathrm{OCH}_{3}$ ), 4.05 (s, 1H, CH-4, pyran), 6.7 (s, 1H, Ar, H-5), 6.87.4 (m, 10H, Ar), 7.53 (d, $J=9.3,2 \mathrm{H}, \mathrm{Ar}), 7.6$ (d, $J=9.3,2 \mathrm{H}$, Ar), 8.2 (d, J=8.5, 1H, Ar, H-8), $12.2\left(\mathrm{~s}, 2 \mathrm{H}, \mathrm{NH}_{2}\right) ;{ }^{13} \mathrm{C}-\mathrm{NMR}$ $\left(\mathrm{DMSO}-d_{6}\right): \delta, 21.9\left(\mathrm{CH}_{2}-3\right), 27.1\left(\mathrm{CH}_{2}-2\right), 29.9\left(\mathrm{CH}_{2}-4\right)$, 31.6 (CH-4, pyran), 46.0 (C-5, pyran), $55.2\left(\mathrm{OCH}_{3}\right), 66.8(\mathrm{C}-$ 3, pyran), 113.0, 113.7, 118.6, 119.8, 124.6, 125.2, 126.9, 130.1, $130.4,130.7,142.7,143.0,144.9,149.0,153.8,156.3,157.2$, $161.1,161.5,162.1,165.9,168.1,169.0$ (Ar-C and CN); MS: $\mathrm{m} / \mathrm{z}(\%): 656\left(\mathrm{M}^{+}, 63\right)$ consistent with the molecular formula $\mathrm{C}_{36} \mathrm{H}_{28} \mathrm{~N}_{6} \mathrm{O}_{5} \mathrm{~S}$. Anal. Calcd. C, 65.84; H, 4.30; N, 12.80; Found C, $66.08 ; \mathrm{H}, 4.11 ; \mathrm{N}, 12.68 \%$.
2.1.18. 5-Amino-7-(furan-2-yl)-3-((6-methoxy-3,4-dihydronaphthalen-1(2H)-ylidene)amino)-2-((4-phenoxyphenyl)imino)3,7-dihydro-2H-pyrano [2,3-d] thiazole-6-carbonitrile 5f. Yield: 55\%; m.p.: $280^{\circ} \mathrm{C}$; IR $\left(v_{\max } / \mathrm{cm}^{-1}\right): 3475,3334\left(\mathrm{NH}_{2}\right), 2208$ $(\mathrm{CN}) ;{ }^{1} \mathrm{H}-\mathrm{NMR}\left(\mathrm{DMSO}-d_{6}\right): \delta, 1.9\left(\mathrm{~m}, 2 \mathrm{H}, \mathrm{CH}_{2}-3\right), 2.4(\mathrm{t}$, $\left.J=5.9,2 \mathrm{H}, \mathrm{CH}_{2}-2\right), 2.9\left(\mathrm{t}, J=5.7,2 \mathrm{H}, \mathrm{CH}_{2}-4\right), 3.7(\mathrm{~s}, 3 \mathrm{H}$, $\left.\mathrm{OCH}_{3}\right), 4.1$ (s, 1H, CH-4, pyran), 6.2-6.9 (m, 7H, Ar), 7.1 ( $\mathrm{t}, J=7.6,1 \mathrm{H}, \mathrm{C}-4^{\prime}$ of phenyl), 7.5 (d, $\left.J=9.3,2 \mathrm{H}, \mathrm{Ar}\right), 7.6$ (d, $J=9.3,2 \mathrm{H}, \mathrm{Ar}), 7.9-8.2\left(\mathrm{~m}, 5 \mathrm{H}, \mathrm{Ar}\right.$ and $\left.\mathrm{NH}_{2}\right) ;{ }^{13} \mathrm{C}-\mathrm{NMR}$ $\left(\mathrm{DMSO}-d_{6}\right): \delta, 22.2\left(\mathrm{CH}_{2}-3\right), 26.5\left(\mathrm{CH}_{2}-2\right), 29.8\left(\mathrm{CH}_{2}-4\right)$, 33.1 (CH-4, pyran), 42.6 (C-5, pyran), $55.6\left(\mathrm{OCH}_{3}\right), 66.8$ (C-3, pyran), 107.0, 108.0, 110.8, 118.6, 119.8, 124.6, 125.2, $130.1,130.7,142.7,143.0,144.9,146.3,149.0,153.8,156.3$, 157.2, 161.1, 161.5, 162.1, 165.9, 168.1, 169.0 (Ar-C and $\mathrm{CN}) ; \mathrm{MS}: \mathrm{m} / \mathrm{z}(\%): 600,602\left(\mathrm{M}^{+}, 18,30\right)$ consistent with the molecular formula $\mathrm{C}_{34} \mathrm{H}_{27} \mathrm{~N}_{5} \mathrm{O}_{4} \mathrm{~S}$. Anal. Calcd. C, 67.87; $\mathrm{H}, 4.52$; N, 11.64; Found C, 67.56; H, 4.23; N, 11.89\%.

2.1.19. 2-((4-Bromophenyl)imino)-5-((dimethylamino)methy lene)-3-((6-methoxy-3,4-dihydronaph thalene-1(2H)-ylidene) amino)thiazolidin-4-one 6. A mixture of compound $4 a$ $(0.001 \mathrm{~mol})$ and DMF-DMA $(2 \mathrm{~mL})$ was refluxed for $\sim 1 \mathrm{~h}$; after cooling, the solid product was filtered, washed with petroleum ether, dried, and recrystallized from dilute ethanol to give compound 6. Yield: $87 \%$; m.p.: $236^{\circ} \mathrm{C}$; IR $\left(v_{\max } / \mathrm{cm}^{-1}\right)$ : $1670(\mathrm{C}=\mathrm{O}) ;{ }^{1} \mathrm{H}-\mathrm{NMR}\left(\mathrm{DMSO}-d_{6}\right): \delta ; 1.7\left(\mathrm{~m}, 2 \mathrm{H}, \mathrm{CH}_{2}-3\right)$, $2.59\left(\mathrm{t}, J=6.1,2 \mathrm{H}, \mathrm{CH}_{2}-2\right), 2.7\left(\mathrm{t}, J=5.6,2 \mathrm{H}, \mathrm{CH}_{2}-4\right), 3.6$, $3.7\left(2 \mathrm{~s}, 6 \mathrm{H},-\mathrm{NMe}_{2}\right), 3.8,\left(\mathrm{~s}, 3 \mathrm{H}, \mathrm{OCH}_{3}\right), 6.7(\mathrm{~s}, 1 \mathrm{H}, \mathrm{Ar}$, $\mathrm{CH}-5), 6.8$ (d, J=8.8, 1H, Ar, CH-7), $7.4(\mathrm{~d}, J=8.6,2 \mathrm{H}, \mathrm{Ar}$, $\left.\mathrm{CH}-3^{\prime}, 5^{\prime}\right), 7.5$ (s, 1H, =CH-N), 7.7 (d, J=8.6, 2H, Ar, CH, $\left.2^{\prime}, 6^{\prime}\right) 8.04(\mathrm{~d}, J=8.8,1 \mathrm{H}, \mathrm{Ar}, \mathrm{CH}-8) ;{ }^{13} \mathrm{C}-\mathrm{NMR}$ (DMSO$\left.d_{6}\right): \delta ; 22.4\left(\mathrm{CH}_{2}-3\right), 26.5\left(\mathrm{CH}_{2}-2\right), 29.2\left(\mathrm{CH}_{2}-4\right), 35.9$ $\left(-\mathrm{NMe}_{2}\right), 55.6\left(\mathrm{OCH}_{3}\right), 86.2,110.2,110.6,112.5,113.6$, $117.8,124.8,128.0,128.1,131.2,139.1,142.8,149.6,160.3$, 167.4 (Ar-C, CN and $\mathrm{C}=\mathrm{O}$ ); MS: $\mathrm{m} / \mathrm{z}(\%): 498,501\left(\mathrm{M}^{+}\right.$, $58,56)$, consistent with the molecular formula $\mathrm{C}_{23} \mathrm{H}_{23} \mathrm{Br}$ $\mathrm{N}_{4} \mathrm{O}_{2} \mathrm{~S}$. Anal. Calcd. C, 55.31; H, 4.64; N, 11.22; Found C, 55.09; H, 4.54; N, 10.98\%.

2.1.20. Ethyl-2-((4-bromophenyl)imino)-3-((6-methoxy-3,4-di hydronaphthalen-1(2H)-ylidene) amino)-5-methyl-2,3-dihydrothiazolo [4,5-b]pyridine-6-carboxylate (7) and 2-((4bromo phenyl)imino)-3-((6-methoxy-3,4-dihydronaphthalen1(2H)-ylidene)amino)-5-methyl-2,3-dihydrothiazolo [4,5-b] pyridin-6-yl) ethanone 8 . To a solution of compound $\mathbf{6}$ $(0.005 \mathrm{~mol})$ and ammonium acetated $(0.5 \mathrm{gm})$ in glacial acetic acid $(5 \mathrm{~mL})$, ethyl acetoacetoacetate or acetylacetone $(0.005 \mathrm{~mol})$ was added. The mixture was heated under reflux for $4 \mathrm{~h}$;; after completion of the reaction and cooling, the product was poured onto ice cold water, dried, and recrystallized from the suitable solvent to give compounds $\mathbf{7}$ and $\mathbf{8}$.

2.1.21. Ethyl-2-((4-bromophenyl)imino)-3-((6-methoxy-3,4dihydronaphthalen-1(2H)-ylidene) amino)-5-methyl-2,3dihydrothiazolo [4,5-b]pyridine-6-carboxylate 7. Yield: 83\%; recrystallized from ethyl alcohol; m.p.: $90^{\circ} \mathrm{C}$; IR $\left(v_{\max } / \mathrm{cm}^{-1}\right)$ : $1710(\mathrm{C}=\mathrm{O}) ;{ }^{1} \mathrm{H}-\mathrm{NMR}\left(\mathrm{DMSO}-d_{6}\right): \delta, 1.2(\mathrm{t}, J=6.8,3 \mathrm{H}$, $\left.-\mathrm{CH}_{2}-\mathrm{CH}_{3}\right), 1.7,\left(\mathrm{~m}, 2 \mathrm{H}, \mathrm{CH}_{2}-3\right), 2.1$ (s, $3 \mathrm{H}, \mathrm{CH}_{3}$, pyridine), $2.6\left(\mathrm{t}, J=5.6,2 \mathrm{H}, \mathrm{CH}_{2}-2\right), 2.7\left(\mathrm{t}, J=5.3,2 \mathrm{H}, \mathrm{CH}_{2}-4\right), 3.8(\mathrm{~s}$, 
$\left.3 \mathrm{H}, \mathrm{OCH}_{3}\right), 4.1\left(\mathrm{~m}, 2 \mathrm{H},-\mathrm{CH}_{2}-\mathrm{CH}_{3}\right), 6.7$ (s, 1H, Ar, H-5), 6.8 (d, $J=9.3,1 \mathrm{H}, \mathrm{Ar}, \mathrm{H}-7), 7.3-7.7(\mathrm{~m}, 5 \mathrm{H}, \mathrm{Ar}), 8.0(\mathrm{~d}, J=9.3$, $1 \mathrm{H}, \mathrm{Ar}, \mathrm{CH}-8) ;{ }^{13} \mathrm{C}-\mathrm{NMR}$ (DMSO- $\left.d_{6}\right): \delta, 14.5\left(\mathrm{CH}_{2} \mathrm{CH}_{3}\right)$, $18.4\left(\mathrm{CH}_{3}\right.$ - pyridine $), 22.2\left(\mathrm{CH}_{2}-3\right), 27.1\left(\mathrm{CH}_{2}-2\right), 29.9$ $\left(\mathrm{CH}_{2}-4\right), 55.6\left(\mathrm{OCH}_{3}\right), 61.01\left(\mathrm{CH}_{2} \mathrm{CH}_{3}\right), 112.9,113.0$, $113.07,115.5,115.9,123.1,124.9,125.4,127.1,130.7,130.8$, $132.3,140.4,148.6,155.6,162.5,163.5,170.3$ (Ar-C, CN and $\mathrm{C}=\mathrm{O})$; MS: $\mathrm{m} / \mathrm{z}(\%): 564,565.7,\left(\mathrm{M}^{+}, 54,53\right)$ consistent with the molecular formula $\mathrm{C}_{27} \mathrm{H}_{25} \mathrm{Br} \mathrm{N} \mathrm{N}_{4} \mathrm{O}_{3} \mathrm{~S}$. Anal. Calcd. C, 57.35; H, 4.46; N, 9.91; Found C, 57.10; H, 4.27; N, 9.86\%.

2.1.22. 2-((4-Bromophenyl)imino)-3-((6-methoxy-3,4-dihydronaphthalen-1(2H)-ylidene)amino)-5-methyl-2,3-dihydrothiazolo [4,5-b]pyridin-6-yl) ethanone 8. Yield: 80\%; Crystallized from n-hexane; m.p.: $128^{\circ} \mathrm{C}$; IR $\left(v_{\max } / \mathrm{cm}^{-1}\right): 1714$ $(\mathrm{C}=\mathrm{O}) ;{ }^{1} \mathrm{H}-\mathrm{NMR}\left(\mathrm{DMSO}-d_{6}\right): \delta, 1.7\left(\mathrm{~m}, 2 \mathrm{H}, \mathrm{CH}_{2}-3\right), 2.1(\mathrm{~s}$, $3 \mathrm{H}, \mathrm{CH}_{3}$, pyridine), $2.3\left(\mathrm{~s}, 3 \mathrm{H}, \mathrm{COCH}_{3}\right), 2.7\left(\mathrm{~m}, 2 \mathrm{H}, \mathrm{CH}_{2^{-}}\right.$ 2), $2.9\left(\mathrm{t}, J=5.9,2 \mathrm{H}, \mathrm{CH}_{2}-4\right), 3.8\left(\mathrm{~s}, 3 \mathrm{H}, \mathrm{OCH}_{3}\right), 6.7(\mathrm{~s}, 1 \mathrm{H}$, Ar, CH-5), 7.3-7.8 (m, 6H, Ar), 8.0 (d, J=9, 1H, Ar, CH-8) ${ }^{13} \mathrm{C}-\mathrm{NMR}\left(\mathrm{DMSO}-d_{6}\right): \delta, 18.2\left(\mathrm{CH}_{3}\right.$, pyridine), $22.2\left(\mathrm{CH}_{2^{-}}\right.$ 3), $27.3\left(\mathrm{CH}_{2}-2\right), 29.7\left(\mathrm{CH}_{2}-4\right), 30.1 \quad\left(\mathrm{COCH}_{3}\right), 55.7$ $\left(\mathrm{OCH}_{3}\right), 102.07,103.1,113.07,113.7,121.9,124.9,126.9$, $129.1,130.7,132.3,134.9,143.4,147.6,155.6,161.1,162.5$, 163.5 (Ar-C and CN), $196.5(\mathrm{C}=\mathrm{O}) ; \mathrm{MS}: \mathrm{m} / \mathrm{z}(\%): 535,537$ $\left(\mathrm{M}^{+}, 37,36\right)$ consistent with the molecular formula $\mathrm{C}_{26} \mathrm{H}_{23}$ Br $\mathrm{N}_{4} \mathrm{O}_{2}$ S. Anal. Calcd. C, 58.32; H, 4.33; N, 10.46; Found C, 58.06; H, 3.97; N, 10.12\%.

2.1.23. 2-((4-Bromophenyl)imino)-3-((6-methoxy-3,4-dihydronaphthalen-1(2H)-ylidene)amino)-5-(oxo/thioxo)-2,3,4,5tetrahydrothiazolo [4,5-b]pyridine-6-carbonitrile 9 and 10 . To a solution of compound $6(0.005 \mathrm{~mol})$ in ethanolic sodium hydroxide solution $(0.12 \mathrm{gm}$ sodium metal in $20 \mathrm{~mL}$ absolute ethanol), malononitrile or cyanothioacetamide $(0.005 \mathrm{~mol})$ was added. The mixture was refluxed for $3 \mathrm{~h}$, the excess solvent was evaporated under reduced pressure, and the solid product was collected by filtration, washed with water, dried, and recrystallized from ethanol to give the products 9 and 10, respectively.

2.1.24. 2-((4-Bromophenyl)imino)-3-((6-methoxy-3,4-dihydronaphthalen-1(2H)-ylidene)amino)-5-oxo-2,3,4,5-tetrahydrothiazolo [4,5-b]pyridine-6-carbonitrile 9. Yield: 83\%; m.p.: $224^{\circ} \mathrm{C}$; IR $\left(v_{\max } / \mathrm{cm}^{-1}\right): 3330(\mathrm{NH}), 2212(\mathrm{CN}), 1660(\mathrm{C}=\mathrm{O})$; ${ }^{1} \mathrm{H}-\mathrm{NMR}\left(\mathrm{DMSO}-d_{6}\right): \delta, 1.7\left(\mathrm{~m}, 2 \mathrm{H}, \mathrm{CH}_{2}-3\right), 2.6(\mathrm{t}, J=6.2$, $\left.2 \mathrm{H}, \mathrm{CH}_{2}-2\right), 2.73\left(\mathrm{t}, \mathrm{J}=5.7,2 \mathrm{H}, \mathrm{CH}_{2}-4\right), 3.7\left(\mathrm{~s}, 3 \mathrm{H}, \mathrm{OCH}_{3}\right)$, 6.7 (s, 1H, Ar, CH-5), 6.8 (d, J=8.8, 1H, Ar, H-7), $7.3(\mathrm{~m}$, 2H, Ar,), 7.5 (s, 1H, CH-4, pyridine), 7.6 (m, 2H, Ar), 8.0 (d, J=8.8, 1H, Ar, CH-8), 8.5 (s, 1H, NH). ${ }^{13} \mathrm{C}-\mathrm{NMR}$ $\left(\mathrm{DMSO}-d_{6}\right): \delta, 22.2\left(\mathrm{CH}_{2}-3\right), 27.2\left(\mathrm{CH}_{2}-2\right), 29.9\left(\mathrm{CH}_{2}-4\right)$, $55.6\left(\mathrm{OCH}_{3}\right), 87.8$ (C-5b pyridine), 112.9, 113.7, 116.2, $121.1,125.4,126.8,130.7,131.7,132.1,135.4,142.8,144.8$, $159.0,159.02,160.8,166.9,167.1$ (Ar-C, $\mathrm{CN}$ and $\mathrm{C}=\mathrm{O})$; MS: $\mathrm{m} / \mathrm{z}(\%): 518,520\left(\mathrm{M}^{+}, 45,44\right)$ consistent with the molecular formula $\mathrm{C}_{24} \mathrm{H}_{18} \mathrm{BrN}_{5} \mathrm{O}_{2} \mathrm{~S}$. Anal. Calcd. C, 55.39; H, 3.49; N, 13.46; Found C, 55.09; H, 3.12; N, 13.18\%.

2.1.25. 2-((4-Bromophenyl)imino)-3-((6-methoxy-3,4-dihydronaphthalen-1(2H)-ylidene)amino)-5-thioxo -2,3,4,5-tetrahydrothiazolo [4,5-b]pyridine-6-carbonitrile 10. Yield:
81\%; m.p.: $286^{\circ} \mathrm{C}$; IR $\left(v_{\max } / \mathrm{cm}^{-1}\right): 3380(\mathrm{NH}), 2220(\mathrm{CN})$; ${ }^{1} \mathrm{H}-\mathrm{NMR}\left(\mathrm{DMSO}-d_{6}\right): \delta, 1.7\left(\mathrm{~m}, 2 \mathrm{H}, \mathrm{CH}_{2}-3\right), 2.58(\mathrm{t}$, $\left.J=6.3,2 \mathrm{H}, \mathrm{CH}_{2}-2\right), 2.7\left(\mathrm{t}, J=5.4,2 \mathrm{H}, \mathrm{CH}_{2}-4\right), 3.77(\mathrm{~s}, 3 \mathrm{H}$, $\left.\mathrm{OCH}_{3}\right), 6.7$ (s, $\left.1 \mathrm{H}, \mathrm{Ar}, \mathrm{CH}-5\right), 6.8(\mathrm{~d}, J=8.7,1 \mathrm{H}, \mathrm{Ar}, \mathrm{CH}-$ 7), $7.4(\mathrm{~d}, J=8.6,2 \mathrm{H}, \mathrm{Ar}), 7.5(\mathrm{~s}, 1 \mathrm{H}$, pyridine $), 7.6(\mathrm{~d}$, $J=8.6,2 \mathrm{H}, \mathrm{Ar}$ ), 8.0 (d, J=8.7, 1H, Ar, CH-8), 8.5 (s, $1 \mathrm{H}$, $\mathrm{NH}) ;{ }^{13} \mathrm{C}-\mathrm{NMR}\left(\mathrm{DMSO}-d_{6}\right): \delta, 22.2\left(\mathrm{CH}_{2}-3\right), 27.2\left(\mathrm{CH}_{2}-2\right)$, $29.9\left(\mathrm{CH}_{2}-4\right), 55.6\left(\mathrm{OCH}_{3}\right), 85.3(\mathrm{C}-5 \mathrm{~b}$ pyridine), 112.9, $113.7,116.2,121.1,125.4,126.8,130.7,131.7,132.0,135.4$, 142.7, 144.8, 159.0, 159.9, 160.8, 166.8, 167.1 (Ar-C, CN and $\mathrm{C}=\mathrm{S}) ; \mathrm{MS}: \mathrm{m} / \mathrm{z}(\%): 535,537\left(\mathrm{M}^{+}, 26,25\right.$, ) consistent with the molecular formula $\mathrm{C}_{24} \mathrm{H}_{18} \mathrm{BrN}_{5} \mathrm{OS}_{2}$. Anal. Calcd. C, 53.73; H, 3.38; N, 13.05; Found C, 53.25; H, 3.13; N, 12.86\%.

2.1.26. 5-((1H-Benzo [d]imidazol-2-ylamino)methylene)-2-(4bromophenylimino)-3-((6-methoxy-3,4 -dihydronaphtha-len1(2H)-ylidene)amino)thiazolidin-4-one 11 and 2-(4-bromophenyl-imino)-3-((6-methoxy-3,4-dihydronaphthalen-1(2H)-ylidene)amino)-5-((thiazol-2-ylamino) methylene)thiazolidin-4-one 12. To a mixture of the enaminone $6(0.005$ $\mathrm{mol})$ in glacial acetic acid $(15 \mathrm{~mL}), 2$-aminobenz- imidazole or 2-aminothiazole was added. The mixture was allowed to react under reflux for $2 \mathrm{~h}$., and the excess solvent was evaporated under vacuum. The solid was collected by filtration, washed with water, dried, and recrystallized from the suitable solvent to give the products 11 and 12 .

2.1.27. 5-((1H-Benzo [d]imidazol-2-ylamino)methylene)-2(4-bromophenylimino)-3-((6-methoxy-3,4 -dihydronaphthalen-1(2H)-ylidene)amino)thiazolidin-4-one 11. Yield: 78\%; crystallized from ethyl alcohol; m.p.: $220^{\circ} \mathrm{C}$; IR $\left(v_{\max } / \mathrm{cm}^{-1}\right)$ : 3368, 3290 (2NH), $1665(\mathrm{C}=\mathrm{O}) ;{ }^{1} \mathrm{H}-\mathrm{NMR}\left(\mathrm{DMSO}-d_{6}\right): \delta$, $2.09\left(\mathrm{~m}, 2 \mathrm{H}, \mathrm{CH}_{2}-3\right), 2.7\left(\mathrm{t}, J=6.3,2 \mathrm{H}, \mathrm{CH}_{2}-2\right), 2.9(\mathrm{t}$, $\left.J=5.7,2 \mathrm{H}, \mathrm{CH}_{2}-4\right), 3.7\left(\mathrm{~s}, 3 \mathrm{H}, \mathrm{OCH}_{3}\right), 3.8(\mathrm{~s}, 1 \mathrm{H}, \mathrm{NH}), 6.6-$ 6.9 (m, 3H, Ar), 7.3-8.0 (m, 9H, Ar, ), $8.4(\mathrm{~s}, 1 \mathrm{H}, \mathrm{NH}) ;{ }^{13} \mathrm{C}-$ NMR (DMSO- $\left.d_{6}\right): \delta, 22.0\left(\mathrm{CH}_{2}-3\right), 23.3\left(\mathrm{CH}_{2}-2\right), 29.7$ $\left(\mathrm{CH}_{2}-4\right), 55.6\left(\mathrm{OCH}_{3}\right), 110.9,112.9,113.04,113.7,116.4$ $124.1,126.9,129.2,130.6,132.3,133.5,133.8,133.8,142.5$, 148.2, 161.5, 161.7, 162.4, 163.6, 174.2.0 (Ar-C, CN and $\mathrm{C}=\mathrm{O}) ; \mathrm{MS}: \mathrm{m} / \mathrm{z}(\%): 586,588\left(\mathrm{M}^{+}, 100,98\right)$ consistent with the molecular formula $\mathrm{C}_{28} \mathrm{H}_{23} \mathrm{BrN}_{6} \mathrm{O}_{2} \mathrm{~S}$. Anal. Calcd. C, 57.24; H, 3.95; N, 14.31; Found C, 56.97; H, 3.74; N, 14.02\%.

2.1.28. 2-(4-Bromophenylimino)-3-((6-methoxy-3,4-dihydronaphthalen-1(2H)-ylidene)amino)-5-((thiazol-2-ylamino)methylene)thiazolidin-4-one 12. Yield: 79\%; recrystallized from isopropyl alcohol; m.p.: $152^{\circ} \mathrm{C}$; IR $\left(v_{\max } / \mathrm{cm}^{-1}\right): 3380(\mathrm{NH})$, $1660(\mathrm{C}=\mathrm{O}) ;{ }^{1} \mathrm{H}-\mathrm{NMR}\left(\mathrm{DMSO}-d_{6}\right): \delta, 2.08\left(\mathrm{~m}, 2 \mathrm{H}, \mathrm{CH}_{2}-3\right)$, $2.4\left(\mathrm{t}, J=6.3,2 \mathrm{H}, \mathrm{CH}_{2}-2\right), 2.7\left(\mathrm{t}, J=5.7,2 \mathrm{H}, \mathrm{CH}_{2}-4\right), 3.5(\mathrm{~s}$, $1 \mathrm{H}, \mathrm{NH}), 3.7\left(\mathrm{~s}, 3 \mathrm{H}, \mathrm{OCH}_{3}\right), 6.7$ (d, J=8.5, 1H, Ar), 6.8 (d, $1 \mathrm{H}, J=8.6, \mathrm{Ar}), 7.1-7.4(\mathrm{~m}, 7 \mathrm{H}, \mathrm{Ar}), 7.9$ (d, $J=8.9,1 \mathrm{H}, \mathrm{Ar})$; ${ }^{13}$ C-NMR (DMSO- $\left.d_{6}\right): \delta, 22.0\left(\mathrm{CH}_{2}-3\right), 23.3\left(\mathrm{CH}_{2}-2\right), 29.0$ $\left(\mathrm{CH}_{2}-4\right), 55.6\left(\mathrm{OCH}_{3}\right), 109,112.9,113.04,113.7,124.1$, $126.1,126.9,129.2,130.6,132.3,133.5,133.8,139.8,148.2$, 161.5, 161.7, 163.6, 170.1 (Ar-C and CN); MS: $\mathrm{m} / \mathrm{z}(\%)$ : $553,555\left(\mathrm{M}^{+}, 50,49\right)$ consistent with the molecular formula $\mathrm{C}_{24} \mathrm{H}_{20} \mathrm{BrN}_{5} \mathrm{O}_{2} \mathrm{~S}_{2}$, Anal. Calcd. C, 51.99; H, 3.64; N, 12.63; Found C, 51.78; H, 3.46; N, 12.49\%. 


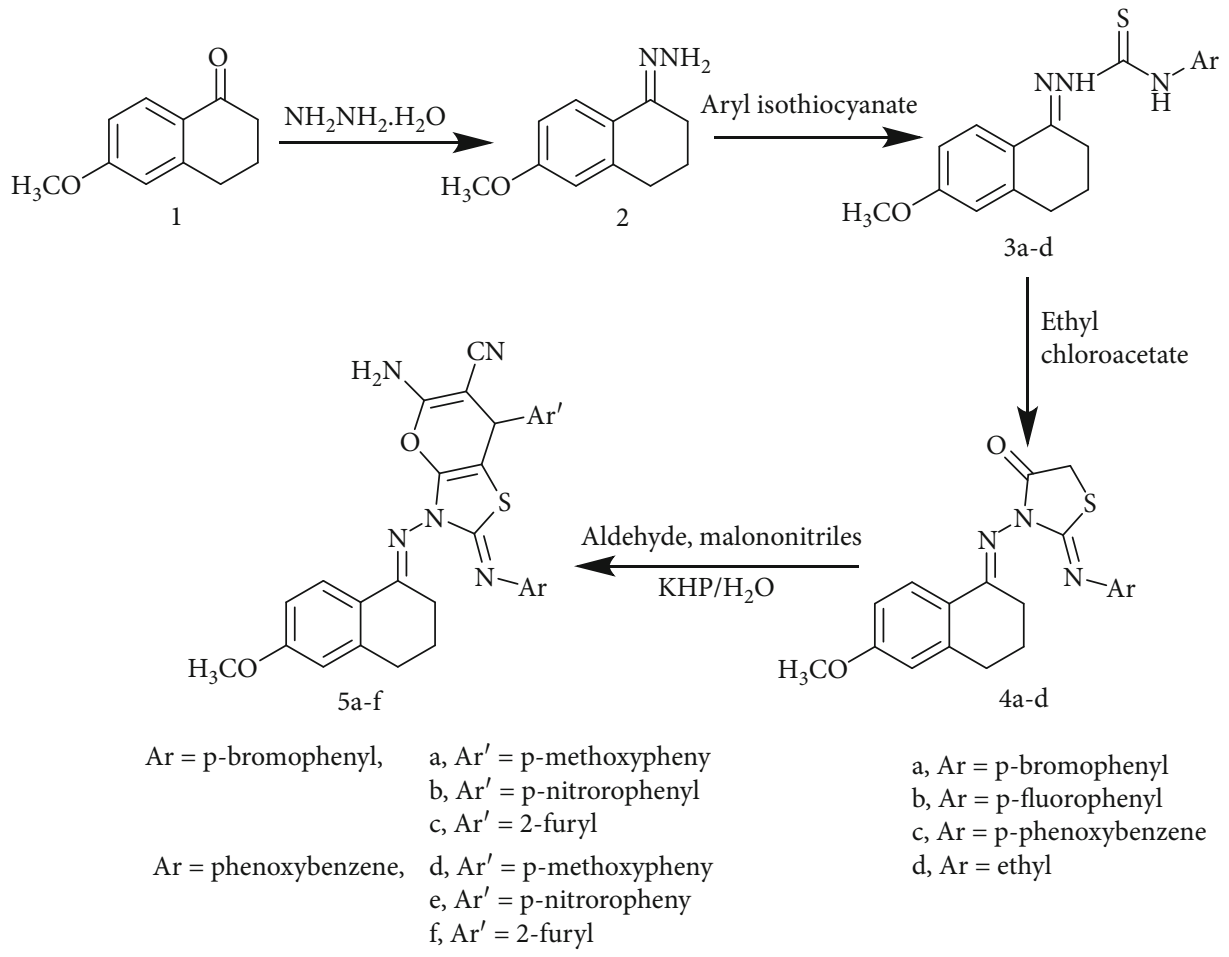

Scheme 1: Synthetic route of compounds 2-5a-f.

2.2. Cell Lines and Cell Culture. Both MCF-7 and MCF10A cells were purchased from American Type Culture Collection (ATCC). Cells were grown in DMEM culture medium (Invitrogen/Life Technologies) supplemented with $10 \%$ FBS (Hyclone, USA), $10 \mu \mathrm{g} / \mathrm{mL}$ insulin (Sigma), and $1 \%$ penicillin-streptomycin antibiotic solution. Chemicals used were of cell culture grade and were purchased from Sigma or Invitrogen. Prior to the assay, cells (cells density $1.2-1.8$ $\times 10,000$ cells/well) were plated in 96-well plate with $100 \mu \mathrm{L}$ medium and were allowed to grow for $24 \mathrm{~h}$.

2.3. In Vitro Cytotoxicity Assay. In vitro cytotoxic activity of the prepared compounds against breast (MCF-7) cancer cells was assessed using MTT assay [24, 25]. The assay depends on the mitochondrial reduction of the colorless 3-(4,5-methyl-2thiazolyl)-2,5-diphenyl-2H-tetrazolium bromide (MTT) within viable cells into a dark blue formazan product. Cells were cultured in DMEM medium supplemented with $10 \%$ FBS at a final concentration of $2 \times 10^{4}$ cells $/ \mathrm{mL}$ in 96 -well plates and incubated in a $5 \% \mathrm{CO}_{2}$ incubator at $37^{\circ} \mathrm{C}$. Twelve hours later, different concentrations $(0.39-100 \mu \mathrm{M})$ of the tested compound $(2 \mu \mathrm{L})$ were added to the cells $\left(2 \times 10^{4}\right)$ in 96 -well plates and cultured at $37^{\circ} \mathrm{C}$ for 3 days. Then, $20 \mu \mathrm{L}$ of MTT solution was added to the cultured cells and incubated for four hours at $37^{\circ} \mathrm{C}$. The supernatant was taken away from each well, and $100 \mu \mathrm{L}$ of DMSO was added to each well to dissolve the formazan crystals. After mixing with a mechanical plate mixer, a microplate reader was used to measure the absorbance of each well at a wavelength of $570 \mathrm{~nm}$. Data were expressed as $\mathrm{IC}_{50}$ $(\mu \mathrm{M})$, i.e., the concentration required to inhibit $50 \%$ of viable cell growth. $\mathrm{IC}_{50}$ values were calculated from the linear regression of the corresponding calibration curves using the Origin ${ }^{\circledR}$
6.1 software. Each experiment was carried out in triplicate with good reproducibility and standard errors.

2.4. Statistical Analysis. Results were analyzed with the help of SPSS 9.0 and were presented as mean \pm SD of three replicates. The mean comparison between different evaluated groups was performed using ANOVA one-way analysis of variance. Statistical significance was defined when $p<0.05$.

\section{Results and Discussion}

3.1. Chemistry. Starting with 6-methoxy-1-tetralone 1, its hydrazine derivative 2 , was prepared as previously reported method [23], reaction of the hydrazine derivative 2 with different aryl isothiocyanates, namely, p-bromophanyl, pflourophanyl, p-phenoxybenzene, and ethyl isothiocyanates produced the desired thiosemicarbazides 3a-d in $85-94 \%$ yield. Thiosemicarbazides 3a-d was separately refluxed with ethylchloroacetate in ethanol to give the thiazolidinone derivatives 4a-d in 76-94\% yields. Pyrano thiazole-carbonitrile derivatives $\mathbf{5 a - f}$ were prepared in $55-81 \%$ yields, by heating a mixture of compound $\mathbf{4 a}$ or $\mathbf{4 c}$, different aryl aldehydes namely, p-methoxy benzaldehyde, p-nitrobenzaldehyde, and/or 2-furaldehyde at $50^{\circ} \mathrm{C}$ and malononitrile utilizing distilled water as a solvent and in the presence of catalytic amount of potassium hydrogen phthalate (Scheme 1).

On the other hand, synthesis of the enaminone, 6 was essential to construct biologically active heterocyclic products. Reaction of the thiazolidinone $\mathbf{4 a}$ with dimethylformamidedimethylacetal (DMF-DMA), under solvent-free conditions, produced the enaminone derivative 6 within $1 \mathrm{~h}$., in $87 \%$ yield. The enamine 6 was condensed with ethyl acetoacetate 


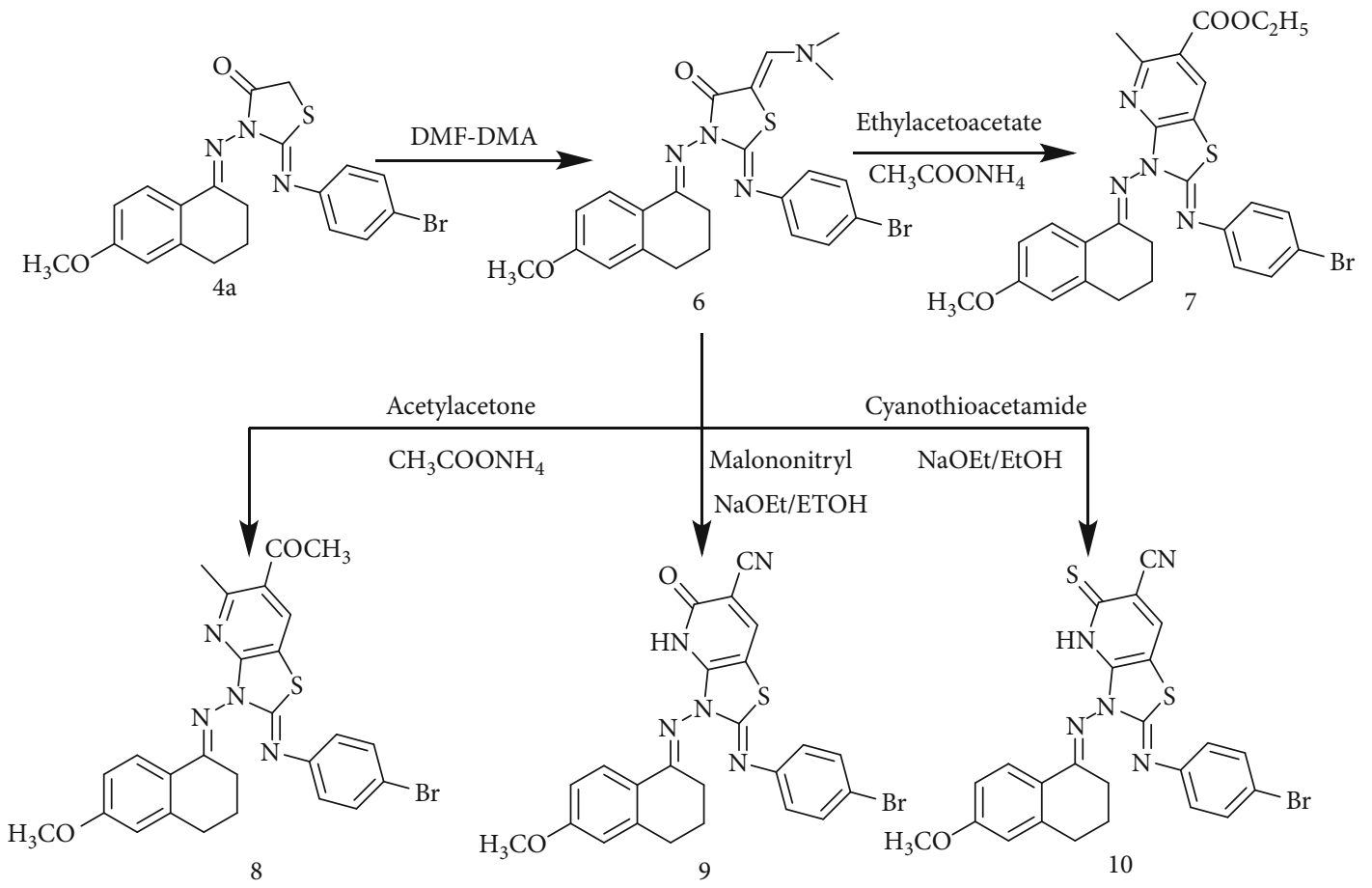

Scheme 2: Synthetic route of compounds 6-10.

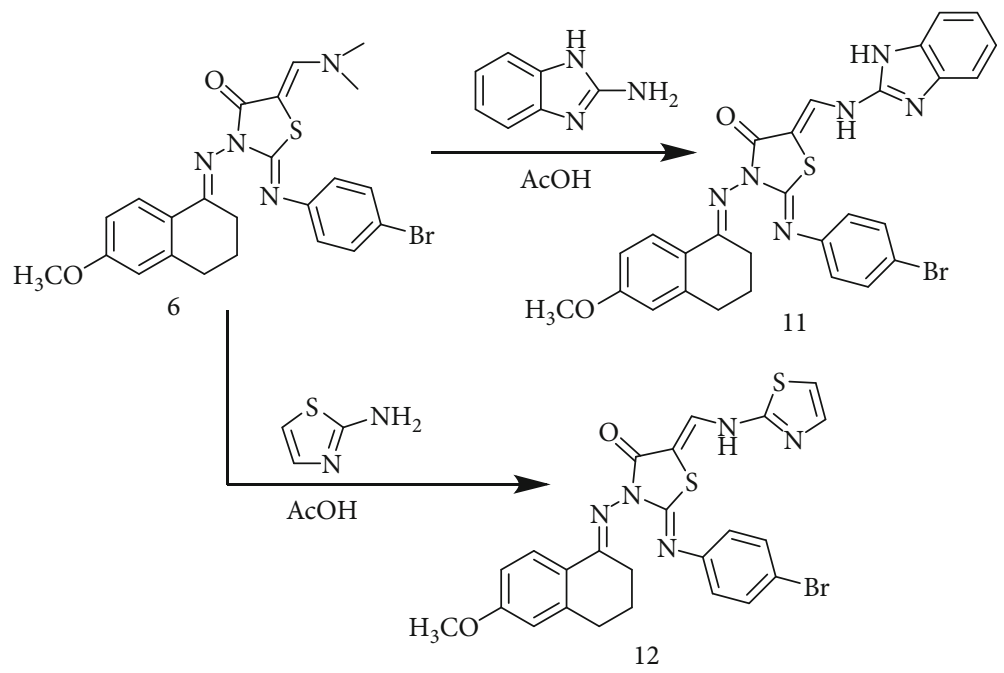

Scheme 3: Synthetic route of compounds 11 and 12.

or acetyl acetone in the presence of ammonium acetate and glacial acetic acid, to afford the thiazolopyridine carboxalate and thiazolo-pyridine ethanone derivatives 7 and 8 , respectively, in 83 and $80 \%$ yields. While, reaction of compound 6 with cyanothioacetamide or malononitrile in ethanolic sodium ethoxide gave thioxo-pyridine or oxo-pyridine carbonitrile derivatives 9 and 10, respectively, in 83 and $81 \%$ yields (Scheme 2).

Finally, reaction of the enaminone $\mathbf{6}$ with 2aminoimidazol or 2-aminothiazol in the presence of glacial acetic acid produced imidazol-thiazolidinone and thiazolothiazolidinone derivatives $\mathbf{1 1}$ and $\mathbf{1 2}$ in 78 and 79\% yields, respectively (Scheme 3 ).
3.2. Cytotoxic Screening. Eleven compounds were investigated in vitro for their activities against breast cancer cell line MCF-7 using MTT assay. The effect of different concentrations of the newly synthesized compounds was evaluated by determining the percentages of viable cells after being exposed to the applied concentrations, compared to Staurosporin as a reference drug. In this screening, all the tested compounds showed potential cytotoxic activities against MCF-7 cells in a dose-dependent manner (Figure 1). Furthermore, it can be seen that the compounds affected cell viability in different patterns. This can be attributed to the differences of cellular response to each compound, depending on the nature of its terminal and functional 

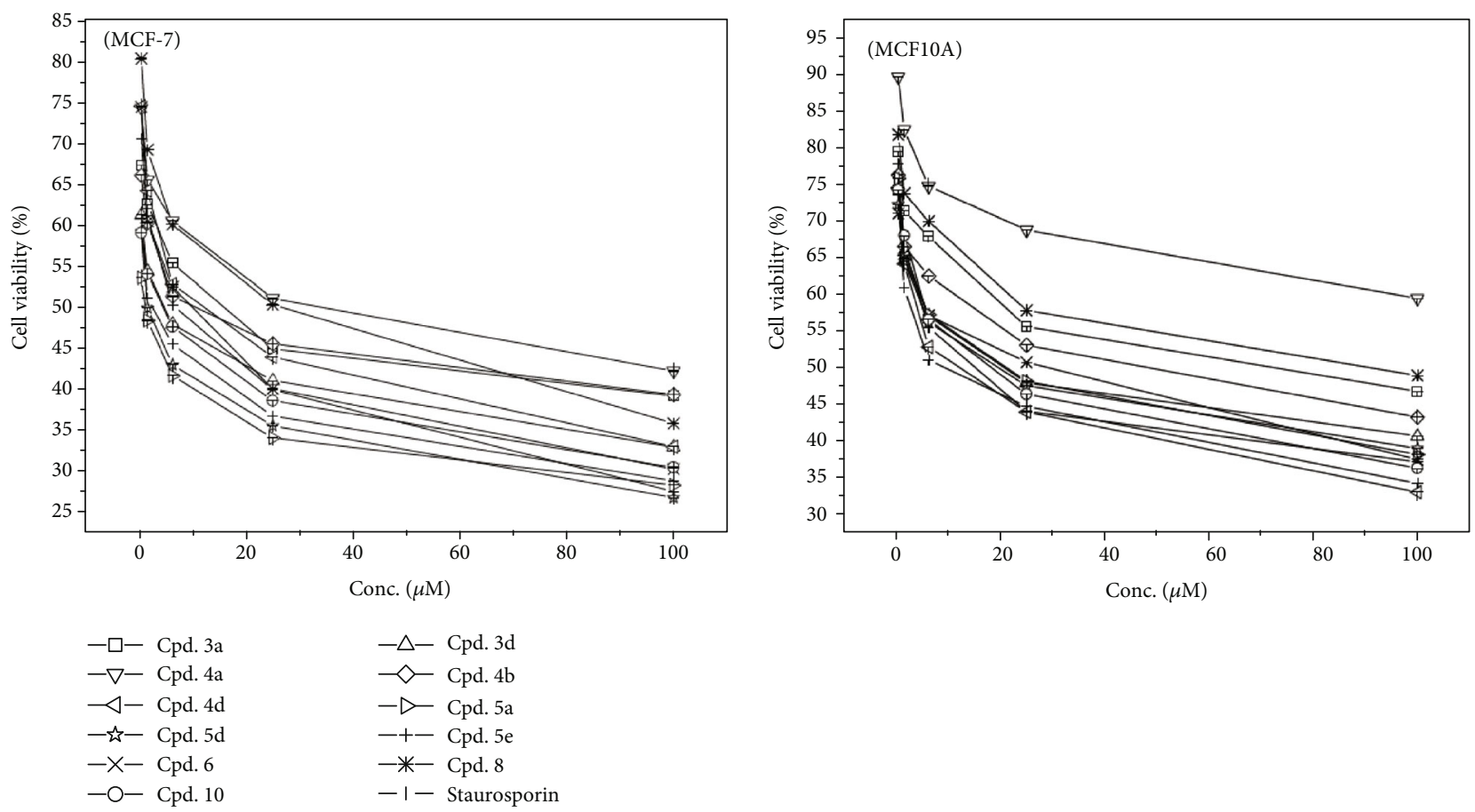

FIGURE 1: Effect of different concentrations of each prepared compound on cell viability of breast cancer cell lines (MCF-7) and normal breast cells (MCF10A).

groups [26, 27]. Results demonstrated that five of the tested compounds $\mathbf{5 a}, \mathbf{5 d}, \mathbf{5 e}, \mathbf{1 0}$, and $\mathbf{3 d}$ showed potential cytotoxic activities against breast cancer cell line MCF-7, recording $\mathrm{IC}_{50}$ values of $0.93 \pm 0.02,1.76 \pm 0.04,2.36 \pm$ $0.06, \quad 2.83 \pm 0.07$, and $3.73 \pm 0.09 \mu \mathrm{M}$, respectively (Table 1). Additionally, it can be seen that these potential compounds had cytotoxic activities higher than the tested positive control (Saturosporin, $\mathrm{IC}_{50} 6.08 \pm 0.15 \mu \mathrm{M}$ ). Comparing these results with those obtained against normal breast cell line (MCF10A) showed that the tested compounds were less toxic toward normal cells. Compound 5a was the most effective against MCF-7 cells and was less toxic than Saturosporin by about 18.45-folds towards MCF01A normal cells. The acquired data revealed that coupling the pyrano ring in this fused heterocyclic ring system was critically influenced the cytotoxic activity. All the tested pyrane containing compounds (5a, 5d, and $\mathbf{5 e}$ ) were the most effective cytotoxic agents and were more potent than Staurosporin $\left(\mathrm{IC}_{50} ; 0.93,1.76\right.$, and $2.36 \mu \mathrm{M}$, respectively, $\mathrm{IC}_{50}$ Staurosporin; $\left.6.08 \mu \mathrm{M}\right)$. The size of $\mathrm{N}$ substitution in thiourea-imino-linked to hydronaphthaline core directly affected the cytotoxic activity. Accordingly, the N-ethyl thiourea derivative $\mathbf{3 d}$ had a very good cytotoxicity $\left(\mathrm{IC}_{50} ; 3.73 \mu \mathrm{M}\right)$. On the other hand, the N-4bromophenyl substitution of thiourea in analog $\mathbf{3 a}$ resulted in more than 3 times decrease in cytotoxicity. Also, a closer antiproliferative potency was exhibited in compound $10\left(\mathrm{IC}_{50} ; 2.83 \mu \mathrm{M}\right)$, in which our core was imino-linked to 5-thioxo-2,3,4,5-tetrahydrothiazole [4,5-b]pyridine-6-carbonitrile ring system. While, the methylation of C-5 and acetylation of C- 6 of the dihydrothiazolo [4,5-b] pyridinyl ring system in compound $\mathbf{8}$ yielded a significantly weaker
TABLE 1: $\mathrm{IC}_{50}$ values of the prepared compounds against breast cancer (MCF-7) and breast normal (MCF10A) cell lines.

\begin{tabular}{lcc}
\hline Comp. No. & \multicolumn{2}{c}{$\mathrm{IC}_{50}(\mu \mathrm{M})$} \\
\hline $3 \mathrm{a}$ & $12.66 \pm 0.33$ & MCF10A \\
\hline $\mathrm{d}$ & $3.73 \pm 0.09$ & $35.42 \pm 0.64$ \\
$4 \mathrm{a}$ & $28.62 \pm 0.74$ & $19.73 \pm 0.51$ \\
$4 \mathrm{~b}$ & $10.22 \pm 0.26$ & $67.95 \pm 0.86$ \\
$4 \mathrm{~d}$ & $10.11 \pm 0.26$ & $29.15 \pm 0.36$ \\
$5 \mathrm{a}$ & $0.93 \pm 0.02$ & $30.74 \pm 0.53$ \\
$5 \mathrm{~d}$ & $1.76 \pm 0.04$ & $17.16 \pm 0.44$ \\
$5 \mathrm{e}$ & $2.36 \pm 0.06$ & $16.33 \pm 0.42$ \\
6 & $7.48 \pm 0.19$ & $14.06 \pm 0.36$ \\
8 & $20.01 \pm 0.52$ & $17.78 \pm 0.16$ \\
10 & $2.83 \pm 0.07$ & $43.69 \pm 0.59$ \\
Staurosporin & $6.08 \pm 0.15$ & $15.01 \pm 0.39$ \\
\hline
\end{tabular}

cytotoxic activity than compound $\mathbf{1 0}\left(\mathrm{IC}_{50} ; 20 \mu \mathrm{M}\right)$. This highlighted the importance of 5-thioxo and 6-carbonitrile functionality for MCF7 antiproliferative activity in this fused heterocyclic ring system.

\section{Conclusion}

In the course of our research work, some new dihydronaphthalene derivatives were synthesized starting with 6methoxy-1-tetralone 1. Cytotoxic evaluation of eleven compounds was estimated against MCF-7 human cancer cells 
(breast cancer) utilizing Staurosporin as a reference drug. Results declared that compounds 5a, 5d, 5e, 10, and $\mathbf{3 d}$ appeared to be the most active products of $\mathrm{IC}_{50}$ values; 0.93 $\pm 0.02,1.76 \pm 0.04,2.36 \pm 0.06,2.83 \pm 0.07$, and $3.73 \pm 0.09$ $\mu \mathrm{M}$, respectively, which were more potent than the reference used (Saturosporin, $\mathrm{IC}_{50} 6.08 \pm 0.15 \mu \mathrm{M}$ ). These active products possessed selectivity and showed lower toxicity than the reference drug. Compound $5 \mathbf{a}$ was the most effective against MCF-7 cells and was less toxic than Saturosporin by about 18.45-folds towards MCF01A normal cells. At the same time, the tested products possessed selectivity and showed lower toxicity than the standard drug used when examined towards the breast normal cells.

\section{Data Availability}

All data generated in this current work are included in the "Results and Discussion" section.

\section{Conflicts of Interest}

The authors declare that the research was conducted in the absence of any commercial or financial relationships that could be construed as a potential conflict of interest.

\section{Authors' Contributions}

The listed authors contributed to this work as described in the following: N.S.A., A.E.S. A.A.K.A., and M.E.H. gave the concepts of the work, interpreted the results and the experimental part, and prepared the manuscript; A.E.-G.E.A. cooperated in the preparation of the manuscript; and E.A.E. performed the cytotoxic analysis of the new compounds. All authors read and approved the final manuscript.

\section{Acknowledgments}

The authors are grateful to the Deanship of Scientific Research, King Saud University, for funding this work through Research Group Project "RGP-172". Also, the authors extend their appreciation to the National Research Center for funding this work through (Project No.; 12060111).

\section{Supplementary Materials}

The supplementary file includes the Spectroscopic charts which support the study. (Supplementary Materials)

\section{References}

[1] F. Bray, J. Ferlay, I. Soerjomataram, R. L. Siegel, L. A. Torre, and A. Jemal, "Global cancer statistics 2018: GLOBOCAN estimates of incidence and mortality worldwide for 36 cancers in 185 countries," CA-Cancer Journal for Clinicians, vol. 68, no. 6, pp. 394-424, 2018.

[2] Y. Wang, C. Wu, Q. Zhang, Y. Shan, W. Gu, and S. Wang, "Design, synthesis and biological evaluation of novel $\beta$ pinene-based thiazole derivatives as potential anticancer agents via mitochondrial-mediated apoptosis pathway," Bioorganic Chemistry, vol. 84, pp. 468-477, 2019.
[3] T. I. de Santana, M. O. Barbosa, P. A. T. M. Gomes, A. C. N. da Cruz, T. G. da Silva, and A. C. L. Leite, "Synthesis, anticancer activity and mechanism of action of new thiazole derivatives," European Journal of Medicinal Chemistry, vol. 144, pp. 874886, 2018.

[4] M. Ansari, M. Shokrzadeh, S. Karima et al., "New thiazole2(3H)-thiones containing 4-(3,4,5-trimethoxyphenyl) moiety as anticancer agents," European Journal of Medicinal Chemistry, vol. 185, p. 111784, 2020.

[5] A. Lozynskyi, B. Zimenkovsky, and R. Lesyk, "Synthesis and anticancer activity of new thiopyrano [2, 3-d] thiazoles based on cinnamic acid amides," Scientia Pharmaceutica, vol. 82, no. 4, pp. 723-733, 2014.

[6] I. Althagafi, N. El-Metwaly, and T. A. Farghaly, "New series of thiazole derivatives: synthesis, structural elucidation, antimicrobial activity, molecular modeling and MOE docking," Molecules, vol. 24, no. 9, p. 1741, 2019.

[7] M. E. Haiba, S. S. Abd el-Karim, R. S. Gouhar, M. I. el-Zahar, and S. A. el-Awdan, "Synthesis and evaluation of antiinflammatory and analgesic activity of some substituted thiazolyl and thaizolidinonyl tetrahydronapthalene derivatives," Medicinal Chemistry Research, vol. 23, no. 7, pp. 3418-3435, 2014.

[8] B. Z. Kurt, I. Gazioglu, F. Sonmez, and M. Kucukislamoglu, "Synthesis, antioxidant and anticholinesterase activities of novel coumarylthiazole derivatives," Bioorganic Chemistry, vol. 59, pp. 80-90, 2015.

[9] J. M. Bueno, M. Carda, B. Crespo et al., "Design, synthesis and antimalarial evaluation of novel thiazole derivatives," Bioorganic Medicinal Chemistry Letters, vol. 26, no. 16, pp. 39383944, 2016.

[10] F. W. Bell, A. S. Cantrell, M. Högberg et al., "Phenethylthiazolethiourea (PETT) compounds, a new class of HIV-1 reverse transcriptase inhibitors. 1. Synthesis and basic structureactivity relationship studies of PETT analogs," Journal of Medicinal Chemistry, vol. 38, no. 25, pp. 4929-4936, 1995.

[11] A. E. M. Abdallah, R. M. Mohareb, and E. A. Ahmed, "Novel pyrano[2,3-d]thiazole and thiazolo[4,5-b]pyridine derivatives: One-pot three-component synthesis and biological evaluation as anticancer agents, c-Met, and Pim-1 kinase inhibitors," Journal of Heterocyclic Chemistry, vol. 56, no. 11, pp. 30173029, 2019.

[12] V. Zav'yalova, A. Zubarev, and A. Shestopalov, "Synthesis and reactions of 3-acetyl-6-methyl-2-(methylthio) pyridine," Russian Chemical Bulletin, vol. 58, no. 9, pp. 1939-1944, 2009.

[13] R. M. Mohareb, M. Y. Zaki, and N. S. Abbas, "Synthesis, antiinflammatory and anti-ulcer evaluations of thiazole, thiophene, pyridine and pyran derivatives derived from androstenedione," Steroids, vol. 98, pp. 80-91, 2015.

[14] B. Narayan Acharya, D. Thavaselvam, and M. Parshad Kaushik, "Synthesis and antimalarial evaluation of novel pyridine quinoline hybrids," Medicinal Chemistry Research, vol. 17, no. 8, pp. 487-494, 2008.

[15] J. Easmon, G. Purstinger, K. S. Thies, G. Heinisch, and J. Hofmann, "Synthesis, structure-activity relationships, and antitumor studies of 2-benzoxazolyl hydrazones derived from alpha-(N)-acyl heteroaromatics," Journal of Medicinal Chemistry, vol. 49, no. 21, pp. 6343-6350, 2006.

[16] M. Z. Gibson, M. A. Nguyen, and S. K. Zingales, "Design, synthesis, and evaluation of (2-(pyridinyl)methylene)-1-tetralone 
chalcones for anticancer and antimicrobial activity," Medicinal Chemistry, vol. 14, no. 4, pp. 333-343, 2018.

[17] Y. K. Marquez-Flores, M. E. Campos-Aldrete, H. SalgadoZamora, J. Correa-Basurto, and M. E. Melendez-Camargo, "Docking simulations, synthesis, and anti-inflammatory activity evaluation of 2-(N-alkyl)amino-3-nitroimidazo[1,2-a]pyridines," Medicinal Chemistry Research, vol. 21, no. 6, pp. 775782, 2012.

[18] S. M. Sondhi, M. Dinodia, and A. Kumar, "Synthesis, antiinflammatory and analgesic activity evaluation of some amidine and hydrazone derivatives," Bioorganic Medicinal Chemistry, vol. 14, no. 13, pp. 4657-4663, 2006.

[19] A. Worachartcheewan, S. Prachayasittikul, R. Pingaew et al., "Antioxidant, cytotoxicity, and QSAR study of 1-adamantylthio derivatives of 3-picoline and phenylpyridines," Medicinal Chemistry Research, vol. 21, no. 11, pp. 3514-3522, 2012.

[20] M. E. Haiba, E. S. Al-Abdullah, N. S. Ahmed, H. A. Ghabbour, and H. M. Awad, "Efficient and easy synthesis of new Ben$\mathrm{zo}[\mathrm{h}]$ chromene and Benzo[h]quinoline derivatives as a new class of cytotoxic agents," Journal of Molecular Structure, vol. 1195, pp. 702-711, 2019.

[21] M. E. Haiba, E. S. Al-Abdullah, H. A. Ghabbour, S. M. Riyadh, and R. M. Abdel-Kader, "Inhibitory activity of benzo[h]quinoline and benzo[h]chromene in human glioblastoma cells," Tropical Journal of Pharmaceutical Research, vol. 15, no. 11, p. 2337, 2016.

[22] M. E. Haiba, E. S. Al-Abdullah, M. M. Edrees, and N. M. Khalifa, "Synthesis and characterization of some substituted 3,4dihydronaphthalene derivatives through different enaminones as potent cytotoxic agents," Drug Research, vol. 65, no. 1, pp. 9-17, 2015.

[23] M. E. Haiba, E. S. Al-Abdullah, and N. M. Hilmy, "Synthesis and cytotoxicity of some new substituted hydronaphthalene derivatives," American Chemical Science Journal, vol. 3, no. 3, pp. 203-220, 2013.

[24] K. Kuida, “Caspase 9," International Journal of Biochemistry and Cell Biology, vol. 32, no. 2, pp. 121-124, 2000.

[25] A. E. Amr, M. el-Naggar, M. al-Omar, E. A. Elsayed, and M. M. Abdalla, "In vitro and in vivo anti-breast cancer activities of some synthesized pyrazolinyl-estran-17-one candidates," Molecules, vol. 23, no. 7, p. 1572, 2018.

[26] M. O. Hengartner, "The biochemistry of apoptosis," Nature, vol. 407, no. 6805, pp. 770-776, 2000.

[27] I. Dolka, M. Król, and R. Sapierzyński, "Evaluation of apoptosis-associated protein (Bcl-2, Bax, cleaved caspase-3 and P53) expression in canine mammary tumors: an immunohistochemical and prognostic study," Research Veterinary Science, vol. 105, pp. 124-133, 2016. 